Defraeye T., Carmeliet J. (2010), A methodology to assess the influence of local wind conditions and building orientation on the convective heat transfer at building surfaces, Environmental Modelling \& Software 25 (12), 1813-1824. http://dx.doi.org/10.1016/j.envsoft.2010.06.002

\title{
A methodology to assess the influence of local wind conditions and building orientation on the convective heat transfer at building surfaces
}

Thijs Defraeye ${ }^{\mathrm{a}, *}$, Jan Carmeliet ${ }^{\mathrm{b}, \mathrm{c}}$

${ }^{a}$ Laboratory of Building Physics, Department of Civil Engineering, Katholieke Universiteit Leuven, Kasteelpark Arenberg 40, 3001 Heverlee, Belgium

${ }^{b}$ Chair of Building Physics, Swiss Federal Institute of Technology Zurich (ETHZ), Wolfgang-Pauli-Strasse 15, 8093 Zürich, Switzerland

${ }^{c}$ Laboratory for Building Science and Technology, Swiss Federal Laboratories for Materials Testing and Research (Empa), Überlandstrasse 129, 8600 Dübendorf, Switzerland

\begin{abstract}
Information on the statistical mean convective heat transfer coefficient $\left(C H T C_{S M}\right)$ for a building surface, which represents the temporally-averaged $C H T C$ over a long time span (e.g. the lifetime of the building), could be useful for example for the optimisation of the performance of solar collectors and ventilated photovoltaic arrays or for preservation analysis of cultural heritage sites. A methodology is proposed to estimate the $C H T C_{S M}$ for a building surface, by combining local wind climate information and information on the $C H T C$, namely $C H T C$ $U_{10}$ correlations, where $U_{10}$ is the mean wind speed at a height of $10 \mathrm{~m}$ above the ground. This methodology is applied to a cubic building for a specific wind climate, where the $C H T C-U_{10}$ correlations are obtained by means of CFD simulations (CFD code Fluent 6.3, realizable k- $\varepsilon$ turbulence model). It is shown that the $C H T C_{S M}$ varied significantly with the orientation of the building surface due to the rather anisotropic wind conditions, where high values are found for surfaces oriented towards the prevailing wind directions, thus for windward conditions. Moreover, the evaluation of the $C H T C_{S M}$ for other wind climates clearly shows that the local wind conditions also can have a significant impact on the overall magnitude of the $C H T C_{S M}$, where differences up to a factor 4 are found in this study. Different levels of complexity for determining the $C_{H T C}$ value are also evaluated and it is found that the required number of CFD simulations can be reduced significantly by using more simplified methods to calculate the $C H T C_{S M}$, without compromising its accuracy. The applicability of the proposed methodology for other building-related applications is also discussed, for example to assess statistical mean pressure coefficients, wind-driven ventilation rates or convective mass transfer coefficients.
\end{abstract}

\section{Keywords}

convective heat transfer coefficient; building facade; building orientation; wind climate; CFD; low-Reynolds number modelling; RANS

\footnotetext{
${ }^{*}$ Corresponding author. Tel.: +32 (0)16321348; fax: +32 (0) 16321980 .

E-mail address: thijs.defraeye@bwk.kuleuven.be
} 
Defraeye T., Carmeliet J. (2010), A methodology to assess the influence of local wind conditions and building orientation on the convective heat transfer at building surfaces, Environmental Modelling \& Software 25 (12), 1813-1824. http://dx.doi.org/10.1016/j.envsoft.2010.06.002

\section{Introduction}

Knowledge on the convective heat transfer at exterior building surfaces is of interest for several building and urban engineering purposes. For energy performance analysis, it is especially relevant for glazed buildings (Sharples, 1984), double-skin facades, greenhouses (Roy et al., 2002), textile buildings (He and Hoyano, 2009) and membrane-cushion buildings or for building components like solar collectors (Sharples and Charlesworth, 1998), solar chimneys and ventilated photovoltaic arrays (Palyvos, 2008). In urban areas, the outdoor thermal climate and building cooling load are determined by the turbulent convective heat fluxes from building surfaces and streets (Barlow et al., 2004; Hagishima et al., 2005), which is particularly of interest for the analysis of urban heat islands (Sailor and Dietsch, 2007). Note that these wind-induced convective heat losses are usually much larger, namely 2 to 7 times, than the radiative losses (Davies, 2004; Loveday and Taki, 1998). Information on convective heat transfer is also often used to quantify convective moisture transfer at building surfaces, by using the heat and mass transfer analogy (Chilton and Colburn, 1934). Both transfer phenomena affect the hygrothermal behaviour within the building envelope since they determine: (1) the drying of facades wetted by wind-driven rain (Janssen et al., 2007a); (2) the risk of surface condensation by undercooling during clear cold nights (Aelenei and Henriques, 2008; Camuffo and Giorio, 2003); and (3) several physical, chemical and biological weathering processes such as microbiological vegetation (algae) and mould growth (Abuku et al., 2009), wet and dry deposition and reaction of pollutants on surfaces (Dolske, 1995; Jonsson et al., 2008), freezethaw degradation (Franke et al., 1998), moisture-induced salt transport, crystallisation and related deterioration (Franke et al., 1998; Poupeleer et al., 2006a, 2006b), interstitial condensation, etc. This hygrothermal behaviour and the related surface phenomena are important factors for the assessment of durability of constructions and for the preservation of cultural heritage (Carmeliet et al., 2009; Hussein and El-Shishiny, 2009; Monforti et al., 2004; Steeman et al., 2009).

These phenomena can be investigated by means of (building) design guides and standards or numerical modelling, such as Building Energy Simulation (BES) programs (Energyplus; ESP-r), Heat-Air-Moisture transfer (HAM) models (Delphin; Janssen et al., 2007b) and Urban Canopy Models (UCM) (Kusaka et al., 2001; Kondo et al., 2005; Masson, 2000), where convective heat transfer is mostly taken into account by means of convective heat transfer coefficients (CHTCs). These CHTCs relate the convective heat flux normal to the wall $q_{c, w}\left(\mathrm{~W} / \mathrm{m}^{2}\right)$ to the difference between the surface temperature at the wall $T_{w}\left({ }^{\circ} \mathrm{C}\right)$ and a reference temperature $T_{r e f}$ $\left({ }^{\circ} \mathrm{C}\right)$, which is generally taken as the outside air temperature. The convective heat flux is assumed positive away from the wall. The $C H T C\left(\mathrm{~W} / \mathrm{m}^{2} \mathrm{~K}\right)$ is defined as:

$$
\text { CHTC }=\frac{q_{c, w}}{\left(T_{w}-T_{r e f}\right)}
$$

In the past, CHTCS for buildings have been mainly quantified by full-scale experiments (Hagishima and Tanimoto, 2003; Ito et al., 1972; Liu and Harris, 2007; Loveday and Taki, 1996; Sharples, 1984), wind-tunnel tests (Quintela and Viegas, 1995) and Computational Fluid Dynamics (CFD) studies (Blocken et al., 2009; Defraeye et al., 2010a, 2010b). A concise review and discussion on these CHTCs for buildings can be found in Defraeye et al. (2010b). Usually, these studies provide estimates for the CHTC by means of linear or power-law correlations of the $C H T C$ with a reference wind speed $U_{\text {ref }}(\mathrm{m} / \mathrm{s})$, for example the mean wind speed at a height of $10 \mathrm{~m}$ above the ground $U_{10}$, for different wind directions. 
Defraeye T., Carmeliet J. (2010), A methodology to assess the influence of local wind conditions and building orientation on the convective heat transfer at building surfaces, Environmental Modelling \& Software 25 (12), 1813-1824. http://dx.doi.org/10.1016/i.envsoft.2010.06.002

Information on these $C H T C-U_{\text {ref }}$ correlations however does not yet provide the actual statistical mean $C H T C$ $\left(C H T C_{S M}\right)$ for a certain surface or point on the building, where the $C H T C_{S M}$ represents the temporally-averaged CHTC over a long time span, e.g. the building or building component lifetime. This $C H T C_{S M}$ is determined by the local wind climate at the building site (wind climate: wind conditions, i.e. wind speed and wind direction, over a long period of time which can for example be monitored at a meteorological station), where the $C H T C_{S M}$ is characterised by a specific occurrence of wind speed, wind direction and terrain-related approach flow conditions, and by the orientation of the building surface with respect to these local wind conditions. Information of such $C_{H T C}$ values could be useful in the analysis of aforementioned building-related phenomena with numerical models which rely on $C H T C s$ (e.g. HAM models), since the $C H T C_{S M}$ could provide more reliable long-term thermal convective boundary conditions. The $C H T C_{S M}$ could for example be applied to determine the optimal location of a solar collector or a ventilated photovoltaic array on a building, in terms of convective heat losses, in order to optimise their long-term (i.e. lifetime) performance. Another example is related to the preservation of cultural heritage sites, where the use of both the $C H T C_{S M}$ and the statistical mean convective moisture transfer coefficient $\left(C M T C_{S M}\right)$ in numerical models could lead to a better prediction of the long-term hygrothermal behaviour in the future and of the related damage processes. Such statistical mean $C H T C$ values can thus be very useful for many of these applications. For other applications, which are more focussed on dynamic effects, the use of "instantaneous" CHTC values, i.e. on an hourly or daily basis, could be more appropriate. Such instantaneous values could be derived by means of $C H T C-U_{10}$ correlations, for example by using hourly wind climate data. This approach is sometimes used in BES and HAM programs, which however often consider a relatively short time period, e.g. a single year.

In this paper, a methodology is proposed to determine the $C H T C_{S M}$ for a building surface, by taking into account the specific local wind conditions. This is done by determining the surface-averaged $C H T C-U_{10}$ correlations for a building surface for several wind directions, for which CFD simulations (validated against wind-tunnel experiments) are used in this study, and by relating them subsequently to the local wind climate, by means of statistical meteorological data. The main aims of this study are: (1) to determine a surface-averaged $C H T C$ which reflects in a realistic way the actual surface-averaged $C H T C$ experienced by a building surface over a long period of time, namely $C_{H T C}$, by using local wind climate information; (2) to show that, for specific local wind conditions, the building orientation can have a significant impact on the resulting $C H T C_{S M}$ value of a building surface; (3) to show that the magnitude of the $C H T C_{S M}$ of a specific building surface can also vary significantly for different wind climates; and (4) to indicate the influence of different levels of complexity for taking the local climate into account while determining the $C H T C_{S M}$ value. This methodology will be applied to the facades of a cubic building, which is a rather generic case study, but the application for more complex building configurations, e.g. in the urban environment, is straightforward. Although the focus will be on the surface-averaged $C H T C$, i.e. of an entire building facade, the methodology is also applicable for a part of a building surface, representing for example the surface of a solar collector, or for a specific point on the surface but also for the building as a whole. Therefore, $C H T C$ denotes the surface-averaged $C H T C$ in the remainder of this paper, unless specified otherwise. Finally, the use of the methodology for other applications, involving pressure coefficients, wind-driven ventilation rates or CMTCs, is discussed. 


\section{Methodology}

\subsection{Statistical meteorological data}

In Section 2, the applied methodology to obtain the $C H T C_{S M}$ for a building surface with a specific orientation is explained, taking into account the local wind conditions. First of all, information on the local wind climate is required. In this study, the statistical meteorological data (hourly mean potential wind speed $U_{p o t}$ and wind direction), obtained in the meteorological station of Eindhoven (The Netherlands) for the period 1971-2000 (made available by the Royal Dutch Meteorological Institute), are used for the analysis, which thus provide a statistically reliable data set, representative for the wind climate at the meteorological station. $U_{p o t}$ is the wind speed at a height of $10 \mathrm{~m}$ for a terrain with an aerodynamic roughness length $z_{0}$ of $0.03 \mathrm{~m}$, and is classified into 12 wind direction categories and 19 wind speed categories, in this case. These categories respectively represent intervals of $30^{\circ}$ from which the wind blows (for wind direction) and intervals of $1 \mathrm{~m} / \mathrm{s}$ (for wind speed). The northern wind direction $\left(0^{\circ}\right)$ contains for example all winds coming from $-15^{\circ}$ to $15^{\circ}$ and the wind speed category $3.5 \mathrm{~m} / \mathrm{s}$ contains all wind speeds within the range 3-4 m/s. These local wind conditions are represented in Figure 1 and in Table 1. In Table 1, the horizontal rows (wind speeds) are denoted by index $i$ and the vertical columns (wind directions) by index $j$. The table specifies the percentage of occurrence $x_{i j}(\%)$ of a certain wind speed $(i)$ for a certain wind direction $(j)$. It is clear that the wind directions between west and south are the most dominant ones. The indication Var/Calm in Table 1 indicates the percentage of occurrence of wind conditions where the wind direction could not clearly be determined due to strong fluctuations or where there is no or a very low wind speed. For the wind climate of Eindhoven, such conditions are found for $4.1 \%$ of the time (see Table 1). Note that often meteorological stations do not report wind speed data as potential wind speeds, i.e. for $z_{0}=$ $0.03 \mathrm{~m}$ and at $10 \mathrm{~m}$ height. This is not required since the wind speed data of the meteorological station $\left(U_{\text {meteo }}\right)$ have to be transformed anyway to be representative for the wind speeds at the building site $\left(U_{\text {site }}\right)$, which is explained in the next section. If requested, $U_{p o t}$ data can be determined by transformation of the original wind speed data at the meteorological station $\left(U_{\text {meteo }}\right)$, using the same methodology as explained in Section 2.2.

\section{$\underline{2.2 \text { Transformation to building site }}$}

If the terrain roughness length at the meteorological station $\left(z_{0, \text { meteo }}\right)$ differs from that at the building site $\left(z_{0, \text { site }}\right)$ or if the height of the meteorological station $\left(H_{\text {meteo }}\right)$, i.e. the height at which the wind speed is measured, is not equal to the reference height at the building site $\left(H_{\text {site }}\right)$, which is $10 \mathrm{~m}$ in this study, the wind speed data of this meteorological station ( $U_{\text {meteo }}$ at height $H_{\text {meteo }}$ ) have to be transformed to be representative for the wind speeds at the building site ( $U_{\text {site }}$ at height $H_{\text {site }}$ ) for a specific wind direction. Information on this transformation of the meteorological data to the wind conditions near the building site can be found in Blocken et al. (2004). The wind speed data at the building site are obtained by scaling the data of the meteorological station with a factor $U_{\text {site }} / U_{\text {meteo }}$ :

$$
U_{\text {site }}=U_{\text {meteo }} \frac{U_{\text {site }}}{U_{\text {meteo }}}=\gamma(j) U_{\text {meteo }}
$$

This scaling factor $\gamma(j)$, which is a function of the specific wind direction $(j)$, can be determined by assuming a logarithmic law for the vertical profile of the mean horizontal wind speed: 
$\gamma(j)=\frac{U_{\text {site }}}{U_{\text {meteo }}}=\frac{u_{A B L, \text { site }}^{*} \ln \left(\frac{H_{\text {site }}+z_{0, \text { site }}}{z_{0, \text { site }}}\right)}{u_{A B L, \text { meteo }}^{*} \ln \left(\frac{H_{\text {meteo }}+z_{0, \text { meteo }}}{z_{0, \text { meteo }}}\right)}$

where ${u_{A B L}}^{*}$ is the friction velocity $(\mathrm{m} / \mathrm{s})$ in the atmospheric boundary layer $(\mathrm{ABL})$ for a specific wind direction.

The ratio of the friction velocities can be approximated by (Simiu and Scanlan, 1986):

$\frac{u_{A B L, \text { site }}^{*}}{u_{A B L, \text { meteo }}^{*}}=\left(\frac{z_{0, \text { site }}}{z_{0, \text { meteo }}}\right)^{0.0706}$

Note that this transformation has to be performed for each wind direction category since for every category, both at the meteorological station and at the building site, a different terrain roughness can be found. For the sake of simplicity, it is assumed in this case that the cubic building is located in a uniform terrain, i.e. with similar terrain roughness for each wind direction, with $z_{0, s i t e}=0.03 \mathrm{~m}$. Thereby, the available $U_{\text {pot }}$ data of the meteorological station of Eindhoven are representative for $U_{10}$ at the building site in this case, i.e. without the use of any transformation.

Note that if the building of interest is located well within the urban environment, the ABL wind speed profile near the building site will differ to some extent from a classical logarithmic law (e.g. Reynolds and Castro, 2008), especially in the lower region of the urban canopy, i.e. the region in between the ground and the characteristic building height. Transformation of the wind speed profiles at the meteorological station to the building site is thereby less straightforward as in the case of an isolated building since Eq.(4) cannot be used anymore. A transformation can however still be achieved in several ways: (1) If a (larger) computational domain is provided where the buildings in the proximity of the building of interest are modelled explicitly, the flow features characteristic for the lower canopy region are explicitly resolved. This technique is frequently applied in many large environmental studies (e.g. Hussein and El-Shishiny, 2009; van Hooff and Blocken, 2010). In this case, a logarithmic ABL profile can be imposed at the inlet of the computational domain (with $z_{0, \text { site }}$ and $U_{\text {site }}$ at height $H_{\text {site }}$ ), by which Eq.(4) can be used for the transformation of the wind speed profiles of the meteorological station; (2) Instead of using Eq.(3) combined with Eq.(4), a specific scaling factor $\gamma(j)$ can be determined which accounts for the non-logarithmic ABL profile at the building site.

\section{$\underline{2.3 C H T C-U_{10} \text { correlations }}$}

Apart from these statistical meteorological data, the surface-averaged $C H T C-U_{10}$ correlations have to be determined for the building surface of interest for each of the 12 wind directions in order to estimate the CHTC for all wind speeds of each wind direction category (see Table 1). The use of available correlations (see Defraeye et al., 2010b) is not always justified since these correlations are derived for a specific building geometry and building surroundings and they are therefore not always representative for the building under consideration. For full-scale measurements, the use of only one or a few particular measuring locations provides an additional source of arbitrariness on the correlations. Moreover, the influence of the wind direction has been generally taken into account by classifying a surface only as windward or leeward in these measurements, which is a rather coarse classification. 
Defraeye T., Carmeliet J. (2010), A methodology to assess the influence of local wind conditions and building orientation on the convective heat transfer at building surfaces, Environmental Modelling \& Software 25 (12), 1813-1824. http://dx.doi.org/10.1016/i.envsoft.2010.06.002

If no representative correlations can be found in literature, with sufficiently detailed wind direction dependency, the $C H T C-U_{10}$ correlations could also be determined directly by means of full-scale experiments, wind-tunnel experiments or CFD simulations for the building surface of interest. Some remarks have to be kept in mind if CHTCs are determined with these techniques: (1) Full-scale experiments have a limited spatial resolution since the CHTCs are only measured at one or a limited number of locations on the building surface so an actual surface-averaged value cannot be obtained. This technique is also only suitable for existing buildings, for example for studies on the preservation of historical buildings, but it cannot be used during the design of buildings. Note that the measurement period for the full-scale experiments can be quite limited since only the correlations have to be obtained (for different wind directions) and statistical information on the occurrence of the wind speed and wind direction is not required. Given a sufficiently long measurement period however, it is also possible to measure the $C H T C_{S M}$ directly; (2) Wind-tunnel tests usually have a higher spatial resolution, which allows to estimate surface-averaged $C H T C$ values to some extent. The thermal measurements however introduce additional difficulties (e.g. Meinders, 1998) with respect to model design, wind-tunnel air conditioning, accessibility of surfaces (e.g. for infrared thermography) and measurement equipment, in comparison with for example pressure measurements, which make these thermal measurements less attractive for practical applications for more complex building configurations; (3) With CFD, the applied turbulence modelling approach determines to a large extent the accuracy of the calculated flow field and thus of the CHTCs, which can be quantified by means of validation experiments. On the other hand, CFD provides a very high spatial resolution and imposes few restrictions to building geometry and surface details by which surfaceaveraged $C H T C$ values can be obtained for all surfaces of interest at once.

Since CFD exhibits advantages with respect to determining (surface-averaged) CHTCs for complex building configurations, compared to other techniques, and since it is used frequently to evaluate flow fields in environmental studies (Hussein and El-Shishiny, 2009; Neofytou et al., 2006; Solazzo et al., 2009; van Hooff and Blocken, 2010; Wakes et al., 2010), the surface-averaged $C H T C-U_{10}$ correlations in this study will be determined by means of CFD (see Section 3). These correlations will be represented by following power-law correlation:

$C H T C=A_{j} U_{10}^{B_{j}}$

where $A_{j}$ and $B_{j}$ are respectively a coefficient and exponent, which are determined for every wind direction $j$. Note that, due to the symmetry of the cubic building, only two wind directions have to be evaluated with CFD to obtain the $C H T C-U_{10}$ correlations for all 12 wind directions, namely $0^{\circ}$ and $30^{\circ}$.

\subsection{Calculation of $\mathrm{CHTC}_{S M}$}

These $C H T C-U_{10}$ correlations allow to determine the $C H T C$ for a given wind direction $j$, with corresponding factors $A_{j}$ and $B_{j}$, for every wind speed $\left(U_{10, i}\right)$ that is found for this direction (see Table 1), namely $C H T C_{i j}$ : $C H T C_{i j}=A_{j} U_{10, i}^{B_{j}}$

Note that for every wind speed category, for example $3-4 \mathrm{~m} / \mathrm{s}$, the mean wind speed of that category $(3.5 \mathrm{~m} / \mathrm{s})$ is used to determine $C_{H T C}$ with the correlation. The $C H T C_{S M}$ for the building surface of interest is obtained by averaging these $C_{H T C_{i j}}$ values by taking into account the occurrence of each wind speed $i$ for a certain wind direction $j$, i.e. $x_{i j}$ : 
Defraeye T., Carmeliet J. (2010), A methodology to assess the influence of local wind conditions and building orientation on the convective heat transfer at building surfaces, Environmental Modelling \& Software 25 (12), 1813-1824. http://dx.doi.org/10.1016/j.envsoft.2010.06.002

$$
\mathrm{CHTC}_{S M}=\sum_{j} \sum_{i} x_{i j} \mathrm{CHTC}_{i j}
$$

Note that the average $C H T C$ for a certain wind direction $j\left(C_{H T C} C_{A V G, j}\right)$ for the building surface of interest can also be obtained, based on the occurrence of each wind speed $i$ :

$$
\text { CHTC }_{A V G, j}=\sum_{i} \frac{x_{i j}}{x_{t o t, j}} \text { CHTC }_{i j}
$$

Here $x_{\text {tot }, j}$ is the percentage of occurrence of a certain wind direction $j$ :

$$
x_{t o t, j}=\sum_{i} x_{i j}
$$

These values are related to the $C H T C_{S M}$ by:

$$
\text { CHTC }_{S M}=\sum_{j} x_{t o t, j} C H T C_{A V G, j}
$$

Although the proposed methodology relies on CFD in this study, the $C H T C-U_{10}$ correlations for different wind directions can be obtained as well by wind-tunnel tests or full-scale experiments. Furthermore, the methodology could also be applied to evaluate the $C H T C_{S M}$ of an entire building, instead of a single building surface, by using the building-averaged $C H T C-U_{10}$ correlation.

\section{Calculation of $C H T C-U_{10}$ correlations by means of CFD}

\subsection{Numerical model}

A cubic building with a height $(H)$ of $10 \mathrm{~m}$ is considered. The size of the computational domain is determined according to the guidelines of Franke et al. (2007) and Tominaga et al. (2008) and is presented in Figure 2, which allows to evaluate different wind directions. The height of the domain is $6 \mathrm{H}$. At the inlet of the domain, the vertical profiles of the mean horizontal wind speed $U$ (logarithmic law), turbulence kinetic energy $k\left(\mathrm{~m}^{2} / \mathrm{s}^{2}\right)$ and turbulence dissipation rate $\varepsilon\left(\mathrm{m}^{2} / \mathrm{s}^{3}\right)$ are imposed, according to Richards and Hoxey (1993), representing a neutral ABL, i.e. where turbulence in the ABL originates only from friction and shear and not from thermal stratification:

$$
\begin{aligned}
& U(z)=\frac{u_{A B L}^{*}}{\kappa} \ln \left(\frac{z+z_{0}}{z_{0}}\right) \\
& k=3.3 u_{A B L}^{*}{ }^{2} \\
& \varepsilon=\frac{u_{A B L}^{*}{ }^{3}}{\kappa\left(z+z_{0}\right)}
\end{aligned}
$$

where $\kappa$ is the von Karman constant (0.4187), $z$ is the height above the ground (m). The friction velocity $u_{A B L}{ }^{*}$ is linked to a reference wind speed, namely $U_{10}$ in this study, which is taken equal to $0.5 \mathrm{~m} / \mathrm{s}$. Note that other wind speeds ( $U_{10}=1$ and $2.5 \mathrm{~m} / \mathrm{s}$ ) are also evaluated (Section 3.3), resulting in Reynolds numbers from $3.4 \times 10^{5}$ to $1.7 \times 10^{6}$. The parameter $z_{0}$ is $0.03 \mathrm{~m}$, which corresponds to a land surface with low vegetation (e.g. grass) and isolated obstacles (Wieringa, 1992). The temperature of the approach flow is $10^{\circ} \mathrm{C}$, which is taken as the reference temperature in Eq.(1). From the ABL temperature profiles over a flat terrain (Panofsky and Dutton, 1984), it can be shown that assuming a constant temperature over the height of the ABL is a relatively good approximation for a neutral ABL with a zero heat flux at the ground, if a limited height is considered $(6 \mathrm{H}=60 \mathrm{~m}$ in this case). Wind at two different incidence angles is evaluated in the simulations, namely at incidence angles of $0^{\circ}$ and $30^{\circ}$ (Figure 2). The incidence angle $(\varphi)$ is the angle between the approach flow wind direction and the 
normal to the surface of interest. It is $0^{\circ}$ for flow perpendicular to the surface and increases in a clockwise manner.

The ground boundary is modelled as a no-slip boundary with zero roughness since surface roughness values cannot be specified if low-Reynolds number modelling (LRNM) is used to model the boundary layer (Fluent, 2006). This is one of the major drawbacks of using the LRNM approach, which is explained in Section 3.2. This restriction will inevitably introduce streamwise gradients in the vertical profiles of mean horizontal wind speed and turbulence (Blocken et al., 2007) but this could not be avoided. This change in the vertical profiles was assessed by performing a CFD simulation in an empty computational domain. This simulation is not reported in this paper but showed a change in the profiles in the first meters near the ground surface, which alters the flow field around the building to some extent. This effect is however limited since a short upstream fetch is considered. The ground boundary is taken adiabatic. The exterior surfaces of the building are modelled as no-slip boundaries with zero roughness and have an imposed constant temperature of $20^{\circ} \mathrm{C}$.

For the top boundary of the computational domain, a symmetry boundary condition (slip wall) is used, which assumes that the normal velocity component and the normal gradients at the boundary are zero. Note that other ways to model the top boundary in a more optimised way have been reported by Blocken et al. (2007). This modelling technique however is considered less important in the present case, since a relatively short upstream fetch is considered. Zero static pressure is imposed at the outlet. Note that symmetry boundary conditions are used for the lateral boundaries for an incidence angle of $0^{\circ}$ and inlet or outlet boundary conditions are used for an incidence angle of $30^{\circ}$ (Figure 2).

An appropriate grid is built, based on a grid sensitivity analysis. The grid is a hybrid grid (hexahedral and prismatic cells) consisting of about $3.3 \times 10^{6}$ cells (Figure 2). In order to resolve the boundary layer appropriately, LRNM grids require a high cell density in the wall-normal direction and a small $y^{+}$value (dimensionless wall distance) of the wall-adjacent cell $\left(y^{+} \approx 1\right)$, compared to wall functions $\left(30<y^{+}<500\right)$, where $y^{+}$is defined as:

$y^{+}=\frac{\sqrt{\frac{\tau_{w}}{\rho}} y_{P}}{v}$

where $y_{P}$ is the distance (normal) of centre point $\mathrm{P}$ of the wall-adjacent cell to the wall $(\mathrm{m}), \tau_{w}$ is the shear stress at the wall $\left(\mathrm{kg} / \mathrm{ms}^{2}\right), \rho$ is the air density $\left(\mathrm{kg} / \mathrm{m}^{3}\right)$ and $v$ is the kinematic viscosity of air $\left(\mathrm{m}^{2} / \mathrm{s}\right)$. The highest $y^{+}$ values are attained at the edges of the windward surface but are smaller than 3 at the highest wind speed that is evaluated in this study.

Since $\tau_{w}$ increases with increasing velocity $\left(U_{10}\right)$, the evaluation of higher wind speeds requires that the grid is also sufficiently fine in the boundary-layer region at these wind speeds to have a $y^{+}$value of about 1 . Thereby, the required $y_{P}$ can become very small at high Reynolds numbers $\left(\approx 0.05 \mathrm{~mm}\right.$ for $U_{10}=7.5 \mathrm{~m} / \mathrm{s}$, Defraeye et al., $2010 b$ ) which can entail considerable problems for grid generation and convergence rates. However, Defraeye et al. (2010b) showed that relatively low wind speeds could be used, for ABL flow, to evaluate the forced convective $C H T C-U_{10}$ correlations, since the flow field becomes quasi independent of the Reynolds number at Reynolds numbers above approximately $10^{5}$. Here the Reynolds number was based on the cube height $(H)$ and $U_{10}$. Therefore low wind speeds, and hence a relatively large $y_{P}$, will be used in this study, for LRNM purposes, to determine the $C H T C-U_{10}$ correlations (in Section 3.3). 
Defraeye T., Carmeliet J. (2010), A methodology to assess the influence of local wind conditions and building orientation on the convective heat transfer at building surfaces, Environmental Modelling \& Software 25 (12), 1813-1824. http://dx.doi.org/10.1016/i.envsoft.2010.06.002

\subsection{Numerical simulation}

The simulations are performed with the CFD code Fluent 6.3, which uses the control volume method. Steady Reynolds-Averaged Navier-Stokes (RANS) is used in combination with a turbulence model. The realizable k- $\varepsilon$ model (Shih et al., 1995) is used together with LRNM to take care of the viscosity-affected region, for which the one-equation Wolfshtein model (Wolfshtein, 1969) is used.

Since the accuracy of CFD simulations depends to a large extent on the turbulence-modelling and boundarylayer modelling approach that is used, it is imperative that this accuracy is quantified by means of validation experiments. The accuracy of the realizable k- $\varepsilon$ turbulence model with LRNM was evaluated by means of a CFD validation study (Defraeye et al., 2010a) using wind-tunnel measurements of convective heat transfer on the surfaces of a cube placed in turbulent channel flow at a Reynolds number of $4.6 \times 10^{3}$, based on the cube height and the bulk velocity, of Meinders et al. (1999). A part of the results of this validation study is shown in Figure 3, where the CHTCs on the surfaces of the cube in a vertical and horizontal centreplane from experiments and CFD simulations are given, and where only the results in the central region of the surfaces are shown since discrepancies near the edge zones were attributed to the limited resolution of the experiments in these zones. The simulations produced accurate $C H T C$ predictions, both in magnitude and distribution over the surface, for the windward surface (within the experimental uncertainty of 5\% in the overall part of the central region of the surface) and to a lesser extent for the leeward surface (differences with experimental data $<10 \%$ in the overall part of the central region of the surface).

For the side and top surfaces, the distribution of the CHTC over these surfaces was less accurate. This discrepancy is due to the less accurate flow predictions around bluff bodies, in zones of separation and recirculation (Iaccarino et al., 2003; Murakami et al., 1996), which is a generally known deficiency of the steady RANS approach combined with two-equation turbulence models and is attributed to steady-flow and turbulence modelling of the unsteady flow features. The surface-averaged CHTC values for all vertical surfaces however show an acceptable agreement with the experimental data (see Table 2), especially given the fact that the experimental averaging of the $C H T C$ was quite coarse, particularly at the edge zones. The top surface, which shows a significantly larger discrepancy with the experimental data, is not considered in this study.

Although more advanced turbulence modelling approaches, for example Large-Eddy Simulation (LES), could result in more accurate $C H T C$ results on these surfaces, steady RANS is used to predict the surfaceaveraged CHTCs in this study for several reasons: (1) The previously mentioned validation study showed that an acceptable agreement could be obtained for the surface-averaged $C H T C$ for the vertical surfaces, especially when taking into account that with other techniques, i.e. full-scale or wind-tunnel measurements, this $C H T C$ cannot necessarily be determined more accurately, due to the surface averaging. Note however that the discrepancies of CFD with experimental data can be significantly larger if point values would be compared (see Defraeye et al., 2010a); and (2) Steady RANS is much less computationally expensive than more advanced modelling techniques (e.g. LES) and is therefore frequently used in large-scale building aerodynamics studies (Hussein and El-Shishiny, 2009; Neofytou et al., 2006; Solazzo et al., 2009; van Hooff and Blocken, 2010) and other environmental studies (Wakes et al., 2010), which is within the area of interest of the proposed methodology. Also note that wall functions, which are still often used in building aerodynamics, can lead to significant errors in the predicted CHTC compared to LRNM (differences of $\pm 50 \%$, Defraeye et al., 2010a), 
which are larger than the errors introduced by using steady RANS, when looking at surface-averaged CHTCs (see Table 2).

Note that focus of the CFD study is only on forced convection. The reason for this is that if buoyancy effects are taken into account in the simulations, the flow field and consequently the CHTC would be strongly dependent on the imposed thermal boundary conditions, which would make the obtained correlations less generally applicable. For forced convection, the $C H T C$ (Eq.(1)) is actually not dependent on the magnitude of the imposed surface temperatures $\left(T_{w}\right)$ and reference temperatures $\left(T_{r e f}\right)$. Note that for the "Var/Calm" conditions in Table 1, which represent wind conditions at very low wind speeds or of fluctuating wind direction, the CHTC is taken into account by assuming a constant (low) $C H T C$ value, namely $3.5 \mathrm{~W} / \mathrm{m}^{2} \mathrm{~K}$, which is a representative value for low wind speeds. Apart from buoyancy, radiation is also not considered in the simulations since fixed temperature boundary conditions are used for the building surfaces.

Second-order discretisation schemes are used throughout. The SIMPLE algorithm is used for pressurevelocity coupling. Pressure interpolation is second order. Convergence was assessed by monitoring the velocity, turbulence kinetic energy and temperature on specific locations in the flow field and heat fluxes on the surface of the cube.

\subsection{Results}

In order to obtain a surface-averaged $C H T C-U_{10}$ correlation for a specific incidence angle, simulations at different wind speeds have to be performed for this incidence angle. As already mentioned before, these simulations can be performed at relatively low wind speeds (Defraeye et al., 2010b) for building aerodynamics. Moreover, Defraeye et al. (2010b) also showed that only two or three wind speeds were sufficient to obtain the required correlations with sufficient accuracy. Therefore, simulations were performed for $U_{10}=0.5,1$ and 2.5 $\mathrm{m} / \mathrm{s}$. Due to the symmetry of the building, the evaluation of only two incidence angles was sufficient to provide information on the other incidence angles since they can all be related to one of the surfaces in the two simulated cases. The obtained $C H T C-U_{10}$ correlations are shown in Figure 4 for all incidence angles, namely for $\varphi$ from $0^{\circ}$ to $330^{\circ}$ in steps of $30^{\circ}$ and the factors $A_{\varphi}$ and $B_{\varphi}$, namely the coefficient and exponent (Eq.(5)) for a certain incidence angle $\varphi$, are given in Table 3 . Note that the coefficient $A_{\varphi}$ only has an influence on the magnitude of the $C H T C$ whereas the exponent $B_{\varphi}$ also determines the slope and curvature of the $C H T C-U_{10}$ function. It is clear that the magnitude of the coefficient $A_{\varphi}$ differs significantly with the incidence angle but the exponent $B_{\varphi}$ is relatively constant, with an average of 0.86 . The highest values of the $C H T C$ for a given wind speed are obtained for windward surfaces $\left(\varphi=0^{\circ}\right)$. Note that these $C H T C-U_{10}$ correlations are only valid for isolated cubic bodies in a neutral ABL at high Reynolds and low Richardson numbers, or for comparable configurations. Nevertheless, such correlations can be determined with CFD in a similar way for more complex configurations, for example buildings in an urban environment.

\section{Results}

\subsection{CHTC $_{S M}$}

Using the methodology described in Section 2, the $C H T C_{S M}$ is determined for a vertical surface of the cubic building, i.e. a building facade, for the local wind conditions of Eindhoven. The orientation of the building surface $(\beta)$ is required to determine the $\operatorname{CHTC}_{S M}$ (Eq.(7)), since the factors $A_{\varphi}$ and $B_{\varphi}$ have been determined 
(Section 3.3) for different incidence angles ( $\varphi$ ) (see Table 3), with respect to the building surface of interest, where the incidence angles are however not the same as the wind directions $(\omega)$ (see Table 1), except for a building surface oriented to the north $\left(\beta=0^{\circ}\right)$. Note that a wind direction (e.g. north or $0^{\circ}$ ) always is defined as the direction from which the wind is coming and that a surface orientation (e.g. to the west or $90^{\circ}$ ) is defined as that wind direction to which the surface is perpendicular to (i.e. west or $90^{\circ}$ ), as specified in Figure 5, so for windward conditions. Thereby, the surface orientation $(\beta)$ and the wind direction $(\omega)$ are related to the incidence angle $(\varphi)$ by $\varphi=\omega-\beta$, where $\varphi$ increases in a clockwise manner. For a specific surface orientation $\beta$, the factors $A_{\varphi}$ and $B_{\varphi}$ (Table 3), which are known for different incidence angles $\varphi$, can thereby be linked to the appropriate wind direction $\omega(=\varphi+\beta)$, after which the $C H T C_{i j}$ values can be determined for each wind direction $j$ by means of Eq.(6). For wind coming from the direction of the surface orientation, i.e. a windward surface, the factors $A_{j}$ and $B_{j}$ are the ones at an incidence angle of $0^{\circ}$.

In order to indicate the variability of the $C H T C_{S M}$ with the building surface orientation, the $C H T C_{S M}$ is determined for different surface orientations, namely for surfaces oriented to each of the 12 different wind directions specified in Table 1. No additional CFD simulations are required to determine these $C H T C_{S M}$ 's since

the $C H T C-U_{10}$ correlations, and thereby the factors $A_{\varphi}$ and $B_{\varphi}$, were already determined for the relevant incidence angles.

The resulting CHTC $_{S M}$ values are specified in Figure 6 for the 12 surface orientations, together with the occurrence of each specific wind direction $\left(x_{t o t, j}\right)$ for the wind climate of Eindhoven. First of all, the variation of the $C_{H T C_{S M}}$ with the surface orientation is discussed. The $C H T C_{S M}$ varies between about 10 and $13 \mathrm{~W} / \mathrm{m}^{2} \mathrm{~K}$, which indicates that, for an "anisotropic" wind climate, i.e. a wind climate with specific dominant wind directions, the building orientation has a noticeable influence on the magnitude of the $C H T C_{S M}$ of that building surface. The relative difference between the maximal $\left(C H T C_{S M, \max }\right)$ and minimal $\left(C H T C_{S M, \min }\right)$ values, namely

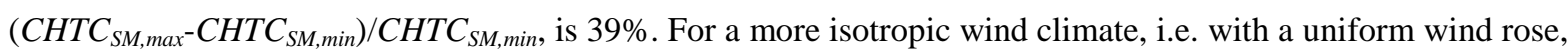
this variability with building orientation will be less. It is also clear that the highest $C H T C_{S M}$ values are found for surfaces oriented to the most dominant wind directions, due to the fact that the highest $C H T C s$ were found for windward surfaces $\left(\varphi \approx 0^{\circ}\right)$ (see Figure 4). As a result, the large peak of $C H T C_{S M}$ in Figure 6 is found at the same angles (at $210^{\circ}-240^{\circ}$ ) as that of $x_{\text {tot } j}$. The smearing out of this $C H T C_{S M}$ peak to nearby surface orientations is due to the fact that the influence of the dominant wind directions is still present at these orientations since the surface is still considered to be quite "windward", resulting in high CHTCs (Figure 4). Furthermore, it should be mentioned that, apart from the variation of the $\mathrm{CHTC}_{S M}$ value with the surface orientation, its overall magnitude, i.e. the height of the curve in Figure 6, is determined by the magnitude of the overall mean wind speed at that building site, which can be significantly higher for coastal sites for example. This is investigated more in detail in Section 5.

\subsection{CHTC $_{S M}$ using average wind speeds}

In the previous section, the $C_{S T C}$ was calculated by determining the $C H T C_{i j}$ at each wind speed $i$. It is however possible that only measurement data of the average wind speed for a certain wind direction $j\left(U_{A V G, j}\right)$ are available, e.g. from a wind rose. In this case, a simplified $C H T C_{S M}$, called $C H T C_{S M, S}$, could be determined by calculating the average $C H T C$ for each wind direction $\left(C H T C_{A V G, S, j}\right)$, only using the average wind speed: 
$\operatorname{CHTC}_{A V G, S, j}=A_{j}\left(U_{A V G, j}\right)^{B_{j}}=A_{j}\left(\sum_{i} \frac{x_{i j}}{x_{t o t, j}} U_{10, i}\right)^{B_{j}}$

Thereby, the following $C H T C_{S M, S}$ value is obtained:

$\operatorname{CHTC}_{S M, S}=\sum_{j} x_{t o t, j} \operatorname{CHTC}_{A V G, S, j}=\sum_{j} x_{t o t, j} A_{j}\left(\sum_{i} \frac{x_{i j}}{x_{t o t, j}} U_{10, i}\right)^{B_{j}}$

This simplified approach could however lead to discrepancies with the previously specified method to calculate $C_{H T C_{A V G, j}}$ (Eq.(8)) and could therefore be less correct in predicting the $C H T C_{S M}$, since by combining Eq.(6) and Eq.(8):

$$
\operatorname{CHTC}_{A V G, j}=\sum_{i} \frac{x_{i j}}{x_{t o t, j}} A_{j} U_{10, i}^{B_{j}}=A_{j}\left(\sum_{i} \frac{x_{i j}}{x_{t o t, j}} U_{10, i}^{B_{j}}\right)
$$

Thereby, $\mathrm{CHTC}_{S M}$ can be written as:

$$
\operatorname{CHTC}_{S M}=\sum_{j} x_{t o t, j} \operatorname{CHTC}_{A V G, j}=\sum_{j} x_{t o t, j} A_{j}\left(\sum_{i} \frac{x_{i j}}{x_{t o t, j}} U_{10, i}^{B_{j}}\right)=\sum_{j} \sum_{i} x_{i j} A_{j} U_{10, i}^{B_{j}}
$$

It is clear that Eq.(14) and Eq.(16) do not give the same result unless the exponents $B_{j}$ are equal to one, since:

$$
\sum_{i} \frac{x_{i j}}{x_{t o t, j}} U_{10, i}^{B_{j}} \neq\left(\sum_{i} \frac{x_{i j}}{x_{t o t, j}} U_{10, i}\right)^{B_{j}}
$$

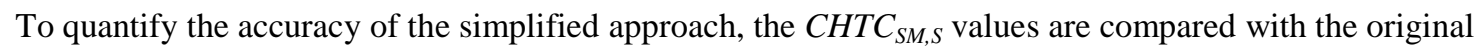
${ }_{C H T C}$ values for a building surface in Figure 6. The difference is however very small which is due to the fact that both factors specified in Eq.(17) are found to differ only about 1.5\% for all surface orientations. The difference is to some extent dependent on the value of the exponent $B_{j}$ and is maximal if $B_{j}$ should be taken equal to about 0.5 but is still below $5 \%$. This indicates that for a certain wind direction, average wind speeds could be used as well, which simplifies the analysis of $C H T C_{S M}$ to some extent and requires less detailed wind climate data.

\section{3. $C H T C_{S M}$ using multiplication factors}

The proposed methodology requires that the $C H T C-U_{10}$ correlations are determined for each of the 12 wind directions, by performing simulations at different wind speeds, which required 6 simulations in this case. Due to the computational expense of CFD simulations and the increase of the required number of simulations with increasing complexity of the building (less symmetry), often simplified methods are explored in building aerodynamics to reduce the number of simulations. A typical example from wind-driven rain research is the cosine projection method, which calculates the wind-driven rainfall intensity on a building surface for oblique wind directions as a (cosine) function of the incidence angle and the wind-driven rainfall intensity at an incidence angle of $0^{\circ}$. Thereby only one simulation at $\varphi=0^{\circ}$ is required. Note that the accuracy of this simplified method is however not always satisfactory, as discussed by Blocken and Carmeliet (2006).

A similar approach could be applied for calculating the $C H T C_{S M}$ by determining the $C H T C-U_{10}$ correlation only for $\varphi=0^{\circ}$, and thus $A_{0^{\circ}}$ and $B_{0^{\circ}}$, and by determining the factor $\chi_{\varphi}=C H T C_{i, \varphi} / C H T C_{i, 0^{\circ}}$ for each incidence angle $\varphi$ at a certain wind speed $U_{10, i}$, where $C H T C_{i, \varphi}$ and $C H T C_{i, 0^{\circ}}$ are the surface-averaged $C H T C s$ at a certain 
wind speed $i$ for an incidence angle of $\varphi$ and of $0^{\circ}$ respectively. Assuming that this multiplication factor $\chi_{\varphi}$ is quasi independent of the wind speed, which is required since $\chi_{\varphi}$ is only determined using CHTC data at a single wind speed, the $C H T C_{i, \varphi}$ value for a certain incidence angle $\varphi$ and wind speed $U_{10, i}$ could be calculated out of CHTC $_{i, 0^{\circ}}$ :

$$
\mathrm{CHTC}_{i, \varphi}=\chi_{\varphi} \mathrm{CHTC}_{i, 0^{\circ}}=\chi_{\varphi} A_{0^{\circ}} U_{10, i}^{B_{0^{\circ}}}
$$

This avoids determining the correlations for all wind directions, which can reduce the number of CFD simulations significantly. For the cubic building of this study, the number of simulations would reduce from 6 ( 2 wind directions, each at 3 wind speeds) to 4 (1 wind direction at 3 wind speeds and 1 wind direction at 1 wind speed). The reduction is even more significant for more complex buildings with less symmetrical shapes. For a rectangular-shaped building for example, the number of simulations reduces from 12 (4 wind directions, each at 3 wind speeds) to 6 ( 1 wind direction at 3 wind speeds and 3 wind directions at 1 wind speed).

To check the accuracy of this simplified approach, the $C H T C_{S M}$ is determined, called the $C H T C_{S M, \chi}$, for all 12 surface orientations and is shown in Figure 6. Note that in this case the correct $\chi_{\varphi}$ factors have to be linked (see Figure 5) to the appropriate wind direction $(\omega=\varphi+\beta)$ for a specific building orientation $(\beta)$, instead of the $A_{\varphi}$ and $B_{\varphi}$ factors, as in Section 4.1. For all surface orientations, these $\chi_{\varphi}$ factors are equal to 1 for incidence angles of $0^{\circ}$ and are specified for all incidence angles in Table 4 for $U_{10}=0.5 \mathrm{~m} / \mathrm{s}$. The differences with the previously determined $C H T C_{S M}$ values are very small. The reason for this good agreement is that the factors $\chi_{\varphi}$ are quasi independent of the magnitude of the wind speed at which they have been determined $(0.5 \mathrm{~m} / \mathrm{s}$ in this case) for all incidence angles. This is a result from the fact that the exponent $B$ of the correlations (Eq.(5)) has almost the same value for all incidence angles, namely about 0.86 , by which the $C H T C_{i, \varphi}$ value increases proportionally to the $C H T C_{i, 0^{\circ}}$ value (Eq.(18)) at higher wind speeds for all incidence angles, resulting in approximately the same values of $\chi_{\varphi}$ for different wind speeds. This can also be noticed from Figure 7, where the variation of these $\chi_{\varphi}$ factors with the wind speed is presented for all incidence angles, where the CHTCs are determined by using the CHTC- $U_{10}$ correlations (Eq.(5) and Table 3).

Defraeye et al. (2010b) however showed that for the leeward surface, the exponent $B$ varies significantly over this surface (between about 0.74 and 0.89 with an average of 0.83 ) where it was about constant (0.85) for the windward surface. Thereby, this simplified approach is not necessarily valid if the CHTC at a single point is considered, which could not be noticed from the present approach since surface-averaged CHTCs are used, apparently leading to a biasing of this phenomenon. Also note that a more distinct variation of the exponent $B$ with the incidence angle could be found for buildings with a more complex and asymmetrical shape.

\section{Application to other wind climates}

In this section, the proposed methodology will be applied to analyse the variability of the $C H T C_{S M}$ with the building orientation for the cubic building for other wind climates than that of Eindhoven. Note that the building is still assumed to be located in the same terrain as in Section 4, namely a uniform terrain with $z_{0, \text { site }}=0.03 \mathrm{~m}$. Meteorological data, similar to those of Table 1, of the stations of Ferrel (Portugal), Granada (Spain) and Cairngorm (United Kingdom) are taken from the European Wind Atlas (Troen and Petersen, 1989). The local wind conditions are presented in Figure 8, where it has to be noted that the scale of Ferrel differs from that of Granada and Cairngorm. Note that all these stations are located in a uniform terrain and that wind speeds $\left(U_{\text {meteo }}\right)$ 
are measured at a height of $10 \mathrm{~m}$. For stations Ferrel and Cairngorm, $z_{0, \text { meteo }}=0.03 \mathrm{~m}=z_{0, \text { site }}$ by which $U_{\text {meteo }}=$ $U_{p o t}=U_{\text {site }}=U_{10}$. For Granada, $z_{0, \text { meteo }}=0.01 \mathrm{~m}$, by which the wind speed data of this station $\left(U_{\text {meteo }}\right)$ have to be corrected in order to be representative for $U_{\text {site }}$, where a different terrain roughness is found $\left(z_{0, \text { site }}=0.03 \mathrm{~m}\right)$. This can be done by using the transformation explained in Section 2.2. Thereby a scaling factor $\gamma(j)$ equal to 0.91 is obtained for all wind directions for the station of Granada. This scaling factor indicates that the wind speeds at the building site will be lower than those recorded at the meteorological station of Granada (see Eq.(2)), which is a result from the larger terrain roughness at the building site. This scaling factor is used to scale the wind speed categories $U_{10, i}$ (see Table 1), by which the overall mean wind speed decreases.

Using the same methodology as in Section 4.1, the $C H T C_{S M}$ values are determined and are specified in Figure 9a for the 12 surface orientations for all wind climates. In Figure 9b, the average wind speed for each wind direction $\left(U_{A V G, j}\right)$ is given for all wind climates. As in Section 4, the influence of building surface orientation on the $\mathrm{CHTC}_{S M}$ can clearly be distinguished, especially for highly anisotropic wind climates, such as that of Ferrel: a distinct $C H T C_{S M}$ peak at building orientations to the north originates from the high occurrence of wind speeds for this direction (see Figure 8a). The relative differences between the maximal and minimal values

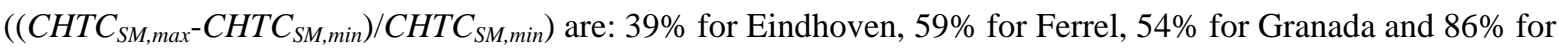
Cairngorm. Apart from that, also a distinct variation in the magnitude of the $C H T C_{S M}$, i.e. the height of the ${ }_{C H T C_{S M}}$ curve, can be noticed for the different wind climates, which is related to the magnitude of the overall mean wind speed $\left(U_{\text {mean }}\right)$ at that building site. This overall mean wind speed $\left(U_{\text {mean }}\right)$ is given by:

$U_{\text {mean }}=\sum_{j} \sum_{i} x_{i j} U_{10, i}$

In Table 5, the overall mean wind speeds at the building sites of the different wind climates are given together with the mean value of the $C H T C_{S M}$, which is obtained by averaging the $C H T C_{S M}$ for all building orientations. Significant differences, i.e. by a factor 4 , are found for the mean $C H T C_{S M}$ between building sites with a low mean wind speed (Granada) and those with a high mean wind speed (Cairngorm). If this mean value of the ${ }_{C H T C_{S M}}$ at the different building sites is correlated with the respective mean wind speed, a very good correlation is obtained: $C H T C_{S M}=2.85 U_{\text {mean }}^{0.90}$ with a correlation coefficient of 0.999 . Thereby, the overall mean wind speed seems to be a good indicator of the mean value of the $C H T C_{S M}$ that could be expected at a building site, whereas this correlation seems to be rather independent of the characteristic percentage of occurrence of each wind direction (i.e. $x_{t o t, j}$ ), which are actually quite different for the wind climates that are considered (Figure 8).

\section{Future perspectives}

In this study, the proposed methodology focussed on convective heat transfer, namely on determining the ${ }^{C H T C_{S M}}$ value for a building surface. The methodology can also be applied for other building-related applications to account for the influence of local wind conditions and building orientation. A typical example can be found for wind pressures at building surfaces. Information on these wind pressures is important for building ventilation and air infiltration through the building envelope (Costola et al., 2009), for air flow through wind towers (Karakatsanis et al., 1986) and for many other ventilation applications (see Khan et al., 2008). Statistical mean values for pressure coefficients or wind-driven ventilation rates, similar to the $C H T C_{S M}$, could be useful for the choice of the location of ventilation openings in buildings for passive cooling by night ventilation, for the orientation of wind towers, etc. Note that, compared to CHTCs, it could be more straightforward and also more 
accurate to obtain information on wind pressures, e.g. pressure coefficients, by means of wind-tunnel tests. Another example is the analysis of the statistical mean ventilation rate or pollutant exchange rate of courtyards or street canyons in urban areas (Liu et al., 2005; Gromke et al., 2008). Furthermore, the spatial distribution of the deposition velocity of particles on building surfaces (e.g. Jonsson et al., 2008) can be analysed with the proposed methodology in order to identify the most critical deposition locations, for example for long-term predictions of pollutant-related damage processes on exterior surfaces of cultural heritage sites. Actually, statistical mean values of all flow quantities on surfaces, e.g. CMTCs, or in the flow field, e.g. wind speeds, can be determined with the proposed methodology, giving a representative value of the "average" quantity which is experienced for a specific building under specific climatic conditions.

\section{Conclusions}

A simple methodology was proposed to obtain an estimate of the statistical mean $C H T C\left(C H T C_{S M}\right)$ for a building surface by combining local wind climate information and information on the surface-averaged $C H T C$, namely forced convective $C H T C-U_{10}$ correlations, for different wind directions, where $U_{10}$ is the mean wind speed at a height of $10 \mathrm{~m}$ above the ground. An entire building facade was considered in this study but the application of the methodology for a smaller surface, e.g. a solar collector, or a specific point on the facade is straightforward. The $C H T C-U_{10}$ correlations were obtained by means of validated CFD simulations (RANS) in this study, although they can also be determined from wind-tunnel tests or full-scale experiments. Note that more advanced turbulence-modelling approaches, such as LES, can improve the accuracy of the CHTC predictions. Nevertheless, LES is more computationally expensive and thus less practical for large-scale environmental studies. Also note that buoyancy and radiation effects were not taken into account in the CFD simulations, by which the focus was only on forced convection, since otherwise the obtained $C H T C-U_{10}$ correlations would be strongly dependent on the imposed thermal boundary conditions, thus less generally applicable.

In this study, a facade of a cubic building was considered, which was located in a wind climate with a few dominant wind directions. It was shown that the $C H T C_{S M}$ varied significantly with the orientation of the building surface for these "anisotropic" wind conditions and that high values were found for surfaces oriented towards the prevailing wind directions, thus for windward conditions. Moreover, different wind climates were evaluated which clearly showed that the local wind conditions can have a significant impact on the overall magnitude of the $C H T C_{S M}$, which is related to the overall mean wind speed found at the building site. Although a very generic building configuration was considered, namely an isolated cubic building, the application of the methodology for more complex building configurations is straightforward, and only requires that the $C H T C-U_{10}$ correlations are determined for the building surface of interest.

Two approaches were proposed to simplify the determination of the ${ } H T C_{S M}$ : (1) Using average wind speed data for a given wind direction instead of considering the distribution of occurrence of each wind speed for that wind direction; and (2) Determining the $C H T C-U_{10}$ correlation only for an incidence angle of $0^{\circ}$ and determining a multiplication factor $\chi_{\varphi}$ for all other incidence angles, which is calculated at one specific wind speed. Both simplified approaches gave a good agreement with the original $C H T C_{S M}$ results. The main advantage of the second approach is that less CFD simulations are required since the $C H T C-U_{10}$ correlations do not have to be determined for every incidence angle. 
Defraeye T., Carmeliet J. (2010), A methodology to assess the influence of local wind conditions and building orientation on the convective heat transfer at building surfaces, Environmental Modelling \& Software 25 (12), 1813-1824. http://dx.doi.org/10.1016/j.envsoft.2010.06.002

Note that once the $C H T C-U_{10}$ correlations are known (i.e. the factors $A$ and $B$ ) for a specific building type at different incidence angles, the proposed methodology allows to determine the $C H T C_{S M}$ for any local wind climate of interest, given that the surrounding terrain roughness is approximately similar, which can be beneficial for design purposes. Therefore future work could focus on determining such $\mathrm{CHTC}-\mathrm{U}_{10}$ correlations for common building types and terrain roughness classes.

Apart from CHTCs, the methodology is also applicable for the assessment of other building-related quantities, such as pressure coefficients, wind-driven ventilation rates or CMTCs.

\section{Acknowledgements}

This research is funded by the Government of Flanders. As a Flemish government institution, IWT-Flanders (Institute for the Promotion of Innovation by Science and Technology in Flanders) supports and stimulates industrial research and technology transfer in the Flemish industry. Their contribution is gratefully acknowledged.

\section{References}

Abuku, M., Janssen, H., Roels, S., 2009. Impact of wind-driven rain on historic brick wall buildings in a moderately cold and humid climate: Numerical analyses of mould growth risk, indoor climate and energy consumption. Energ. Buildings 41 (1), 101-110.

Aelenei, D., Henriques, F.M.A., 2008. Analysis of the condensation risk on exterior surface of building envelopes. Energ. Buildings 40 (10), 1866-1871.

Barlow, J.F., Harman, I.N., Belcher, S.E., 2004. Scalar fluxes from urban street canyons part 1: laboratory simulation. Bound.-Lay. Meteorol. 113 (3), 369-385.

Blocken, B., Carmeliet, J., 2006. On the validity of the cosine projection in wind-driven-rain calculations on buildings. Build. Environ. 41 (9), 1182-1189.

Blocken, B., Defraeye, T., Derome, D., Carmeliet, J., 2009. High-resolution CFD simulations for forced convective heat transfer coefficients at the facade of a low-rise building. Build. Environ. 44 (12), 23962412 .

Blocken, B., Roels, S., Carmeliet, J., 2004. Modification of pedestrian wind comfort in the Silvertop Tower passages by an automatic control system. J. Wind Eng. Ind. Aerodyn. 92 (10), 849-873.

Blocken, B., Stathopoulos, T., Carmeliet, J., 2007. CFD simulation of the atmospheric boundary layer: wall function problems. Atmos. Environ. 41 (2), 238-252.

Camuffo, D., Giorio, R., 2003. Quantitative evaluation of water deposited by dew on monuments. Bound.-Lay. Meteorol. 107 (3), 655-672.

Carmeliet, J., Roels, S., Bomberg, M., 2009. Towards development of methods for assessment of moistureoriginated damage, in: Trechsel, H.R., Bomberg, M. (Eds.), Moisture Control in Buildings: The Key Factor in Mold Prevention. ASTM international, Pennsylvania, pp. 591-605.

Chilton, T.H., Colburn, A.P., 1934. Mass transfer (absorption) coefficients. Ind. Eng. Chemistry 26, 1183-1187.

Costola, D., Blocken, B., Hensen, J.L.M., 2009. Overview of pressure coefficient data in building energy simulation and airflow network programs. Build. Environ. 44 (10), 2027-2036.

Davies, M.G., 2004. Building Heat Transfer, first ed. John Wiley \& Sons Ltd., Chichester, UK. 
Defraeye T., Carmeliet J. (2010), A methodology to assess the influence of local wind conditions and building orientation on the convective heat transfer at building surfaces, Environmental Modelling \& Software 25 (12), 1813-1824. http://dx.doi.org/10.1016/j.envsoft.2010.06.002

Defraeye, T., Blocken, B., Carmeliet, J., 2010a. CFD analysis of convective heat transfer at the surfaces of a cube immersed in a turbulent boundary layer. Int. J. Heat Mass Tran. 53 (1-3), 297-308.

Defraeye, T., Blocken, B., Carmeliet, J., 2010b. Convective heat transfer coefficients for exterior building surfaces: Existing correlations and CFD modelling. Submitted to Energy Conversion \& Management.

Delphin. Delphin: Simulation program for the calculation of coupled heat, moisture, air, pollutant and salt transport (http://www.bauklimatik-dresden.de/delphin [accessed 09.02.2010]).

Dolske, D.A., 1995. Deposition of atmospheric pollutants to monuments, statues, and buildings. Sci. Total Environ. 167 (1-3), 15-31.

EnergyPlus. EnergyPlus Energy Simulation Software (http://apps1.eere.energy.gov/buildings/energyplus/ [accessed 09.02.2010]).

ESP-r. ESP-r source code (http://www.esru.strath.ac.uk/Programs/ESP-r_central.htm http://www.sciencedirect.com/science?_ob=RedirectURL\&_method=externObjLink\&_lo cator=url\&_cdi=5691\&_plusSign=\%2B\&_targetURL=http\%253A\%252F\%252Fwww.esr u.strath.ac.uk\%252FPrograms\%252FESP-r_central.htm[accessed 09.02.2010]).

Fluent, 2006. Fluent 6.3 User's Guide, Lebanon - New Hampshire.

Franke, J., Hellsten, A., Schlünzen, H., Carissimo, B., 2007. Best practice guideline for the CFD simulation of flows in the urban environment. COST Action 732: Quality assurance and improvement of microscale meteorological models, Hamburg, Germany.

Franke, L., Schumann, I., van Hees, R., van der Klugt, L., Naldini, S., Binda, L., Baronio, G., Van Balen, K., Mateus, J., 1998. Damage atlas: classification and analyses of damage patterns found in brick masrony. European Commission Research Report, No. 8, Vol. 2, Fraunhofer IRB Verlag, Germany.

Gromke, C., Buccolieri, R., Di Sabatino, S., Ruck, B., 2008. Dispersion study in a street canyon with tree planting by means of wind tunnel and numerical investigations - Evaluation of CFD data with experimental data. Atmos. Environ. 42 (37), 8640-8650.

Hagishima, A., Tanimoto, J., 2003. Field measurements for estimating the convective heat transfer coefficient at building surfaces. Build. Environ. 38 (7), 873-881.

Hagishima, A., Tanimoto, J., Narita, K., 2005. Intercomparisons of experimental convective heat transfer coefficients and mass transfer coefficients of urban surfaces. Bound.-Lay. Meteorol. 117 (3), 551-576.

He, J., Hoyano, A., 2009. Measurement and simulation of the thermal environment in the built space under a membrane structure. Build. Environ. 44 (6), 1119-1127.

Hussein, A.S., El-Shishiny, H., 2009. Influences of wind flow over heritage sites: A case study of the wind environment over the Giza Plateau in Egypt. Environ. Modell. Softw. 24 (3), 389-410.

Iaccarino, G., Ooi, A., Durbin, P.A., Behnia, M., 2003. Reynolds averaged simulation of unsteady separated flow. Int. J. Heat Fluid Fl. 24 (2), 147-156.

Ito, N., Kimura, K., Oka, J., 1972. A field experiment study on the convective heat transfer coefficient on exterior surface of a building. ASHRAE Trans. 78 (1), 184-191.

Janssen, H., Blocken, B., Roels, S., Carmeliet, J., 2007a. Wind-driven rain as a boundary condition for HAM simulations: analysis of simplified modelling approaches. Build. Environ. 42 (4), 1555-1567. 
Defraeye T., Carmeliet J. (2010), A methodology to assess the influence of local wind conditions and building orientation on the convective heat transfer at building surfaces, Environmental Modelling \& Software 25 (12), 1813-1824. http://dx.doi.org/10.1016/j.envsoft.2010.06.002

Janssen, H., Blocken, B., Carmeliet, J., 2007b. Conservative modelling of the moisture and heat transfer in building components under atmospheric excitation. Int. J. Heat Mass Tran. 50 (5-6), 1128-1140.

Jonsson, L., Karlsson, E., Jönsson, P., 2008. Aspects of particulate dry deposition in the urban environment. J. Hazard. Mater. 153, 229-243.

Karakatsanis, C., Bahadori, M.N., Vickery, B.J., 1986. Evaluation of pressure coefficients and estimation of air flow rates in buildings employing wind towers. Sol. Energy 37 (5), 363-374.

Khan, N., Su, Y., Riffat, S.B., 2008. A review on wind driven ventilation techniques. Energ. Buildings 40 (8), 1586-1604.

Kondo, H., Genchi, Y., Kikegawa, Y., Ohashi, Y., Yoshikado, H., Komiyama, H., 2005. Development of a multi-layer urban canopy model for the analysis of energy consumption in a big city: structure of the urban canopy model and its basic performance. Bound.-Lay. Meteorol. 116 (3), 395-421.

Kusaka, H., Kondo, H., Kikegawa, Y., Kimura, F., 2001. A simple single-layer urban canopy model for atmospheric models: comparison with multi-layer and slab models. Bound.-Lay. Meteorol. 101 (3), 329358.

Liu, C.-H., Leung, D.Y.C., Barth, M.C., 2005. On the prediction of air and pollutant exchange rates in street canyons of different aspect ratios using large-eddy simulation. Atmos. Environ. 39 (9), 1567-1574.

Liu, Y., Harris, D.J., 2007. Full-scale measurements of convective coefficient on external surface of a low-rise building in sheltered conditions. Build. Environ. 42 (7), 2718-2736.

Loveday, D.L., Taki, A.H., 1996. Convective heat transfer coefficients at a plane surface on a full-scale building facade. Int. J. Heat Mass Tran. 39 (8), 1729-1742.

Loveday, D.L., Taki, A.H., 1998. Outside surface resistance: Proposed new value for building design. Build. Services Eng. Research Technol. 19 (1), 23-29.

Masson, V., 2000. A physically-based scheme for the urban energy budget in atmospheric models. Bound.-Lay. Meteorol. 94 (3), 357-397.

Meinders, E.R., 1998. Experimental study of heat transfer in turbulent flows over wall-mounted cubes. PhD thesis, Technische Universiteit Delft, The Netherlands.

Meinders, E.R., Hanjalic, K., Martinuzzi, R.J., 1999. Experimental study of the local convection heat transfer from a wall-mounted cube in turbulent channel flow. Trans. ASME: J. Heat Trans. 121 (3), 564-573.

Monforti, F., Bellasio, R., Bianconi, R., Clai, G., Zanini, G., 2004. An evaluation of particle deposition fluxes to cultural heritage sites in Florence, Italy. Sci. Total Environ. 334-335, 61-72.

Murakami, S., Mochida, A., Ooka, R., Kato, S., Iizuka, S., 1996. Numerical prediction of flow around a building with various turbulence models: comparison of k- $\varepsilon$ EVM, ASM, DSM and LES with wind tunnel tests. ASHRAE Trans. 102 (1), 741-753.

Neofytou, P., Venetsanos, A.G., Vlachogiannis, D., Bartzis, J.G., Scaperdas, A., 2006. CFD simulations of the wind environment around an airport terminal building. Environ. Modell. Softw. 21 (4), 520-524.

Palyvos, J.A., 2008. A survey of wind convection coefficient correlations for building envelope energy systems' modelling. Appl. Therm. Eng. 28 (8-9), 801-808.

Panofsky, H., Dutton, J., 1984. Atmospheric Turbulence, first ed. John Wiley \& Sons, New York, USA. 
Defraeye T., Carmeliet J. (2010), A methodology to assess the influence of local wind conditions and building orientation on the convective heat transfer at building surfaces, Environmental Modelling \& Software 25 (12), 1813-1824. http://dx.doi.org/10.1016/j.envsoft.2010.06.002

Poupeleer, A.S., Roels, S., Carmeliet, J., Van Gemert, D., 2006a. Diffusion-convection transport of salt solutions in cracked porous building materials. Part 1: Parameters, model description and application to cracks. Restoration Buildings Monuments 12 (3), 187-204.

Poupeleer, A.S., Roels, S., Carmeliet, J., Van Gemert, D., 2006b. Diffusion-convection transport of salt solutions in cracked porous building materials. Part 2: Analysis of salt transport in cracked bricks and dead ending cracks. Restoration Buildings Monuments 12 (3), 205-218.

Quintela, D.A., Viegas, D.X., 1995. Convective heat losses from buildings, in: Cermak, J.E., Davenport, A.G., Plate, E.J., Viegas, D.X. (Eds.), Wind Climate in Cities. Kluwer Academic Publishers, The Netherlands, pp. 503-522.

Reynolds, R.T., Castro, I.P., 2008. Measurement in an urban-type boundary layer. Exp. Fluids 45, 141-156.

Richards, P.J., Hoxey, R.P., 1993. Appropriate boundary conditions for computational wind engineering models using the k- $\varepsilon$ turbulence model. J. Wind Eng. Ind. Aerodyn. 46-47, 145-153.

Roy, J.C., Boulard, T., Kittas, C., Wang, S., 2002. PA - Precision Agriculture: convective and ventilation transfers in greenhouses, Part 1: the greenhouse considered as a perfectly stirred tank. Biosyst. Eng. 83 (1), $1-20$.

Sailor, D.J., Dietsch, N., 2007. The urban heat island Mitigation Impact Screening Tool (MIST). Environ. Modell. Softw. 22 (10), 1529-1541.

Sharples, S., 1984. Full-scale measurements of convective energy losses from exterior building surfaces. Build. Environ. 19 (1), 31-39.

Sharples, S., Charlesworth, P.S., 1998. Full-scale measurements of wind-induced convective heat transfer from a roof-mounted flat plate solar collector. Sol. Energy 62 (2), 69-77.

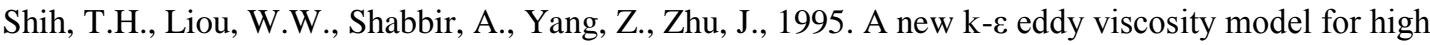
Reynolds number turbulent flows. Comput. Fluids 24 (3), 227-238.

Simiu, E., Scanlan, R.H., 1986. Wind effects on structures: An introduction to wind engineering, second ed. John Wiley \& Sons, New York, USA.

Solazzo, E., Cai, X., Vardoulakis, S., 2009. Improved parameterisation for the numerical modelling of air pollution within an urban street canyon. Environ. Modell. Softw. 24 (3), 381-388.

Steeman, H.-J., Van Belleghem, M., Janssens, A., De Paepe, M., 2009. Coupled simulation of heat and moisture transport in air and porous materials for the assessment of moisture related damage. Build. Environ. 44 (10), 2176-2184.

Tominaga, Y., Mochida, A., Yoshie, R., Kataoka, H., Nozu, T., Yoshikawa, M., Shirasawa, T., 2008. AIJ guidelines for practical applications of CFD to pedestrian wind environment around buildings. J. Wind Eng. Ind. Aerodyn. 96 (10-11), 1749-1761.

Troen, I., Petersen, E.L., 1989. European Wind Atlas, Riso National Laboratory, Roskilde, Denmark.

van Hooff, T., Blocken, B., 2010. Coupled urban wind flow and indoor natural ventilation modelling on a highresolution grid: a case study for the Amsterdam ArenA stadium. Environ. Modell. Softw. 25 (1), 51-65.

Wakes, S.J., Maegli, T., Dickinson, K.J., Hilton, M.J., 2010. Numerical modelling of wind flow over a complex topography. Environ. Modell. Softw. 25 (2), 237-247.

Wieringa, J., 1992. Updating the Davenport roughness classification. J. Wind Eng. Ind. Aerodyn. 41-44, 357368. 
Defraeye T., Carmeliet J. (2010), A methodology to assess the influence of local wind conditions and building orientation on the convective heat transfer at building surfaces, Environmental Modelling \& Software 25 (12), 1813-1824. http://dx.doi.org/10.1016/j.envsoft.2010.06.002

Wolfshtein, M., 1969. The velocity and temperature distribution in one-dimensional flow with turbulence augmentation and pressure gradient. Int. J. Heat Mass Tran. 12 (3), 301-318. 
Defraeye T., Carmeliet J. (2010), A methodology to assess the influence of local wind conditions and building orientation on the convective heat transfer at building surfaces, Environmental Modelling \& Software 25 (12), 1813-1824. http://dx.doi.org/10.1016/i.envsoft.2010.06.002

Figure captions

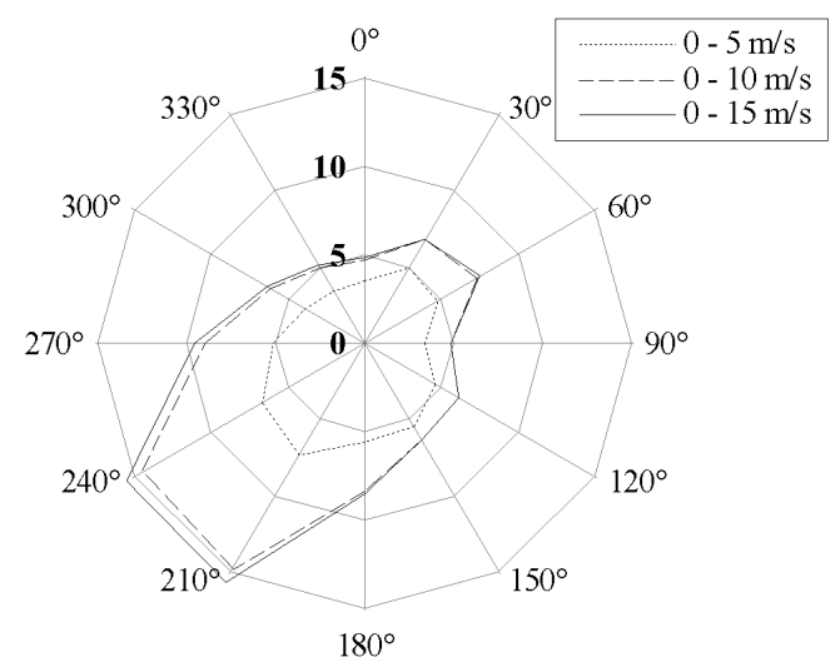

Figure 1: Wind conditions measured at the meteorological station in Eindhoven for the period 1971-2000. Percentage of occurrence (indicated in bold) of hourly wind speeds for different wind speed intervals at specific wind directions (north $=0^{\circ}$, east $=\mathbf{9 0}^{\circ}$ ). The data are obtained from the Royal Dutch Meteorological Institute.

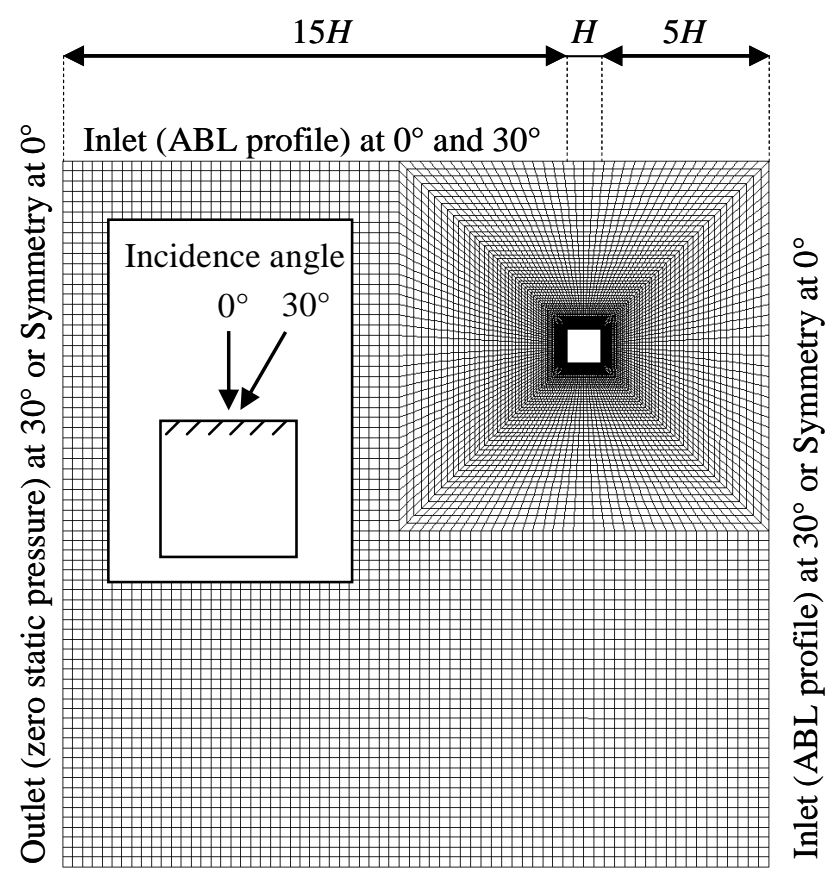

Outlet (zero static pressure) at $0^{\circ}$ and $30^{\circ}$

Figure 2: Top view of the computational domain and grid $(H=$ cube height) with specification of the boundary conditions. The height of the domain is $6 \mathrm{H}$. 

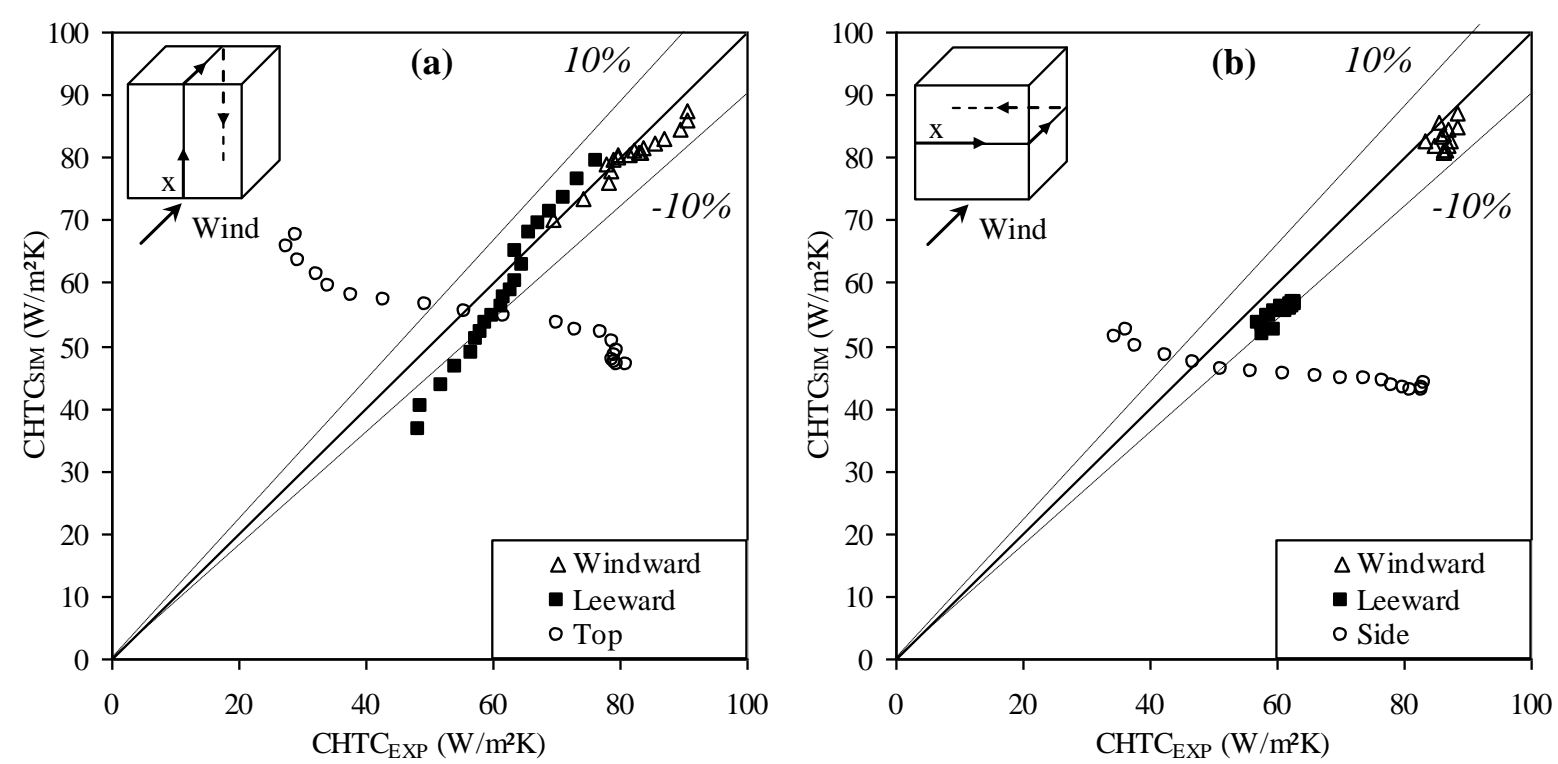

Figure 3: Comparison of the $\mathrm{CHTC}$ on the surfaces of the cube of the wind-tunnel experiment of Meinders et al. (1999) $\left(C H T C_{E X P}\right)$ and the CFD validation study of Defraeye et al. (2010a) $\left(C H T C_{S I M}\right)$ in a vertical (a) and horizontal (b) centreplane. Note that only the results in the central region of the surface $(0.2<x / H<$ 0.8) are shown.

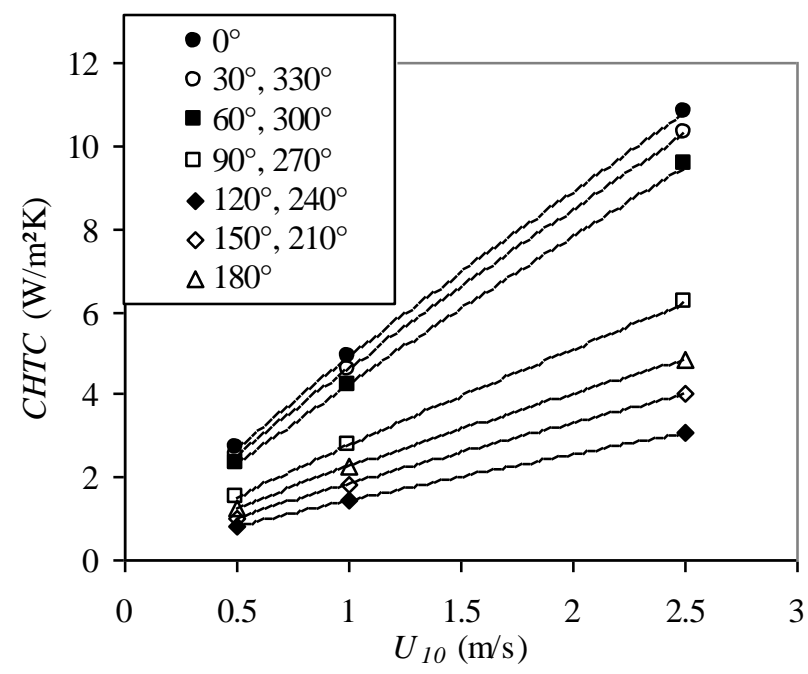

Figure 4: Surface-averaged $C H T C s$, from CFD simulations, at different wind speeds $\left(U_{10}\right)$ for different incidence angles. The power-law approximation curves are represented by the solid lines, indicating a good correlation. 
Defraeye T., Carmeliet J. (2010), A methodology to assess the influence of local wind conditions and building orientation on the convective heat transfer at building surfaces, Environmental Modelling \& Software 25 (12), 1813-1824. http://dx.doi.org/10.1016/j.envsoft.2010.06.002

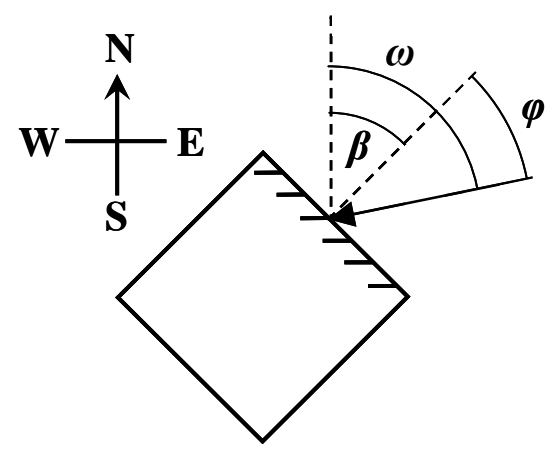

Figure 5: Definition of the building surface orientation $(\beta)$, wind direction $(\omega)$ and incidence angle $(\varphi)$.

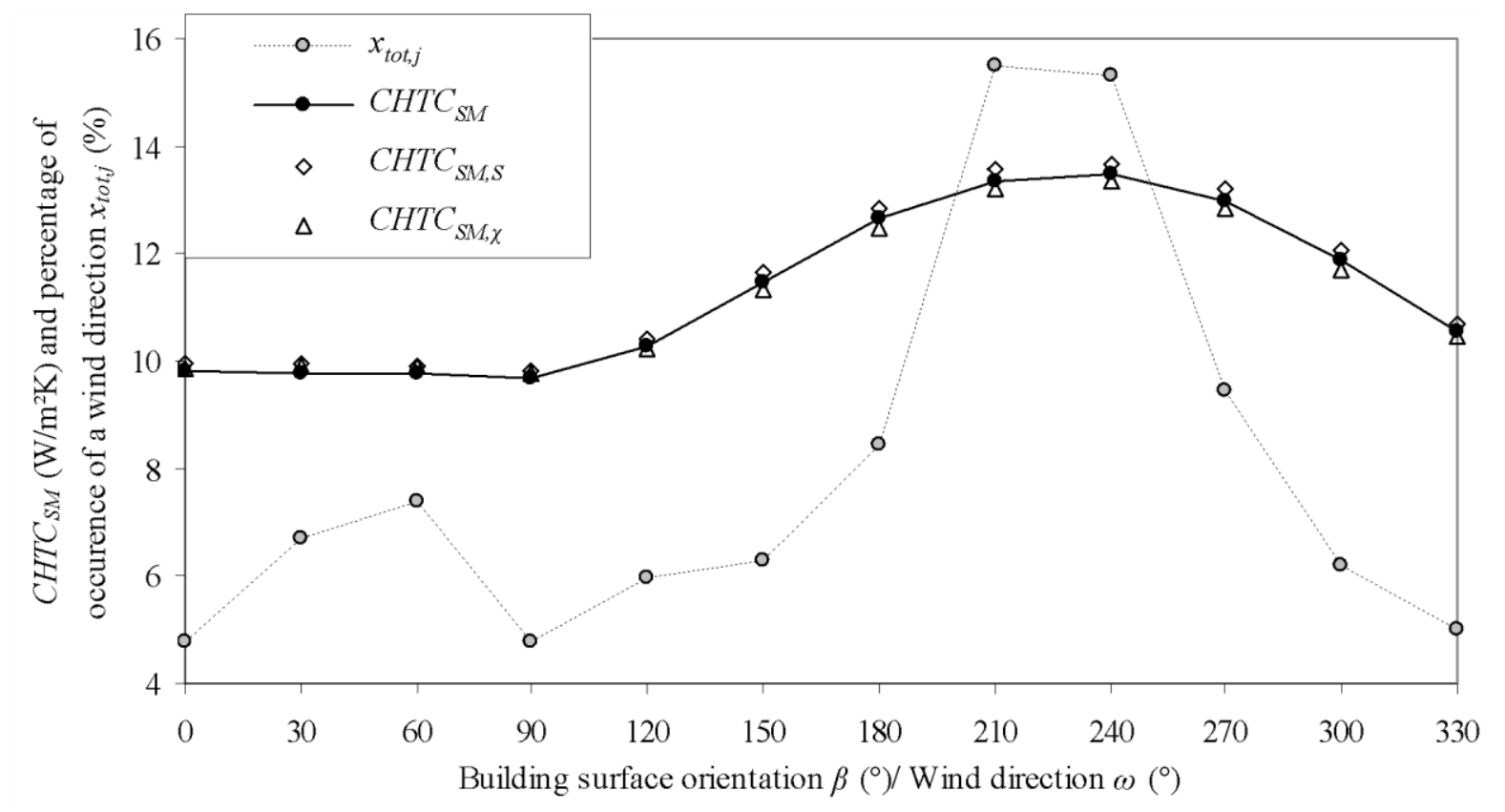

Figure 6: $\mathrm{CHTC}_{S M}, \mathrm{CHTC}_{S M, S}$ (see section 4.2) and $\mathrm{CHTC}_{S M, \chi}$ (see section 4.3) as a function of building surface orientation; and percentage of occurrence of a specific wind direction $\left(x_{t o t, j}\right)$ as a function of wind direction. 
Defraeye T., Carmeliet J. (2010), A methodology to assess the influence of local wind conditions and building orientation on the convective heat transfer at building surfaces, Environmental Modelling \& Software 25 (12), 1813-1824. http://dx.doi.org/10.1016/j.envsoft.2010.06.002

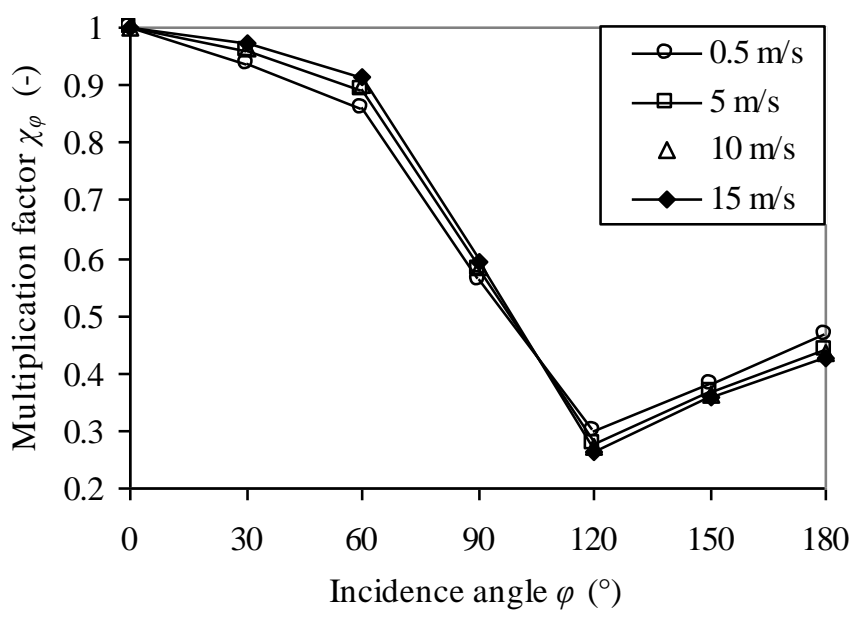

Figure 7: Multiplication factors $\left(\chi_{\varphi}\right)$ for different incidence angles, determined for different wind speeds $U_{10}$, using the $C H T C-U_{10}$ correlation (Eq.(5) and Table 3).

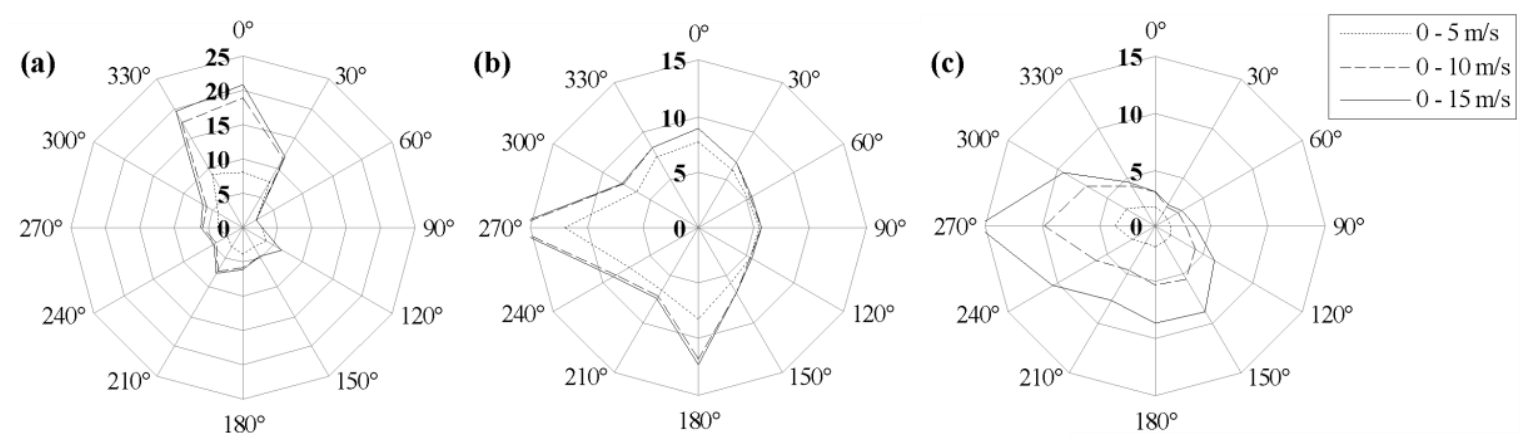

Figure 8: Wind conditions measured at the meteorological stations in: (a) Ferrel (Portugal); (b) Granada (Spain); (c) Cairngorm (United Kingdom). Percentage of occurrence (indicated in bold) of wind speeds for different wind speed intervals at specific wind directions (north $=0^{\circ}$, east $=90^{\circ}$ ). The data are obtained from the European Wind Atlas (Troen and Petersen, 1989). Note that the scale of Ferrel differs from that of Granada and Cairngorm. 
Defraeye T., Carmeliet J. (2010), A methodology to assess the influence of local wind conditions and building orientation on the convective heat transfer at building surfaces, Environmental Modelling \& Software 25 (12), 1813-1824. http://dx.doi.org/10.1016/j.envsoft.2010.06.002
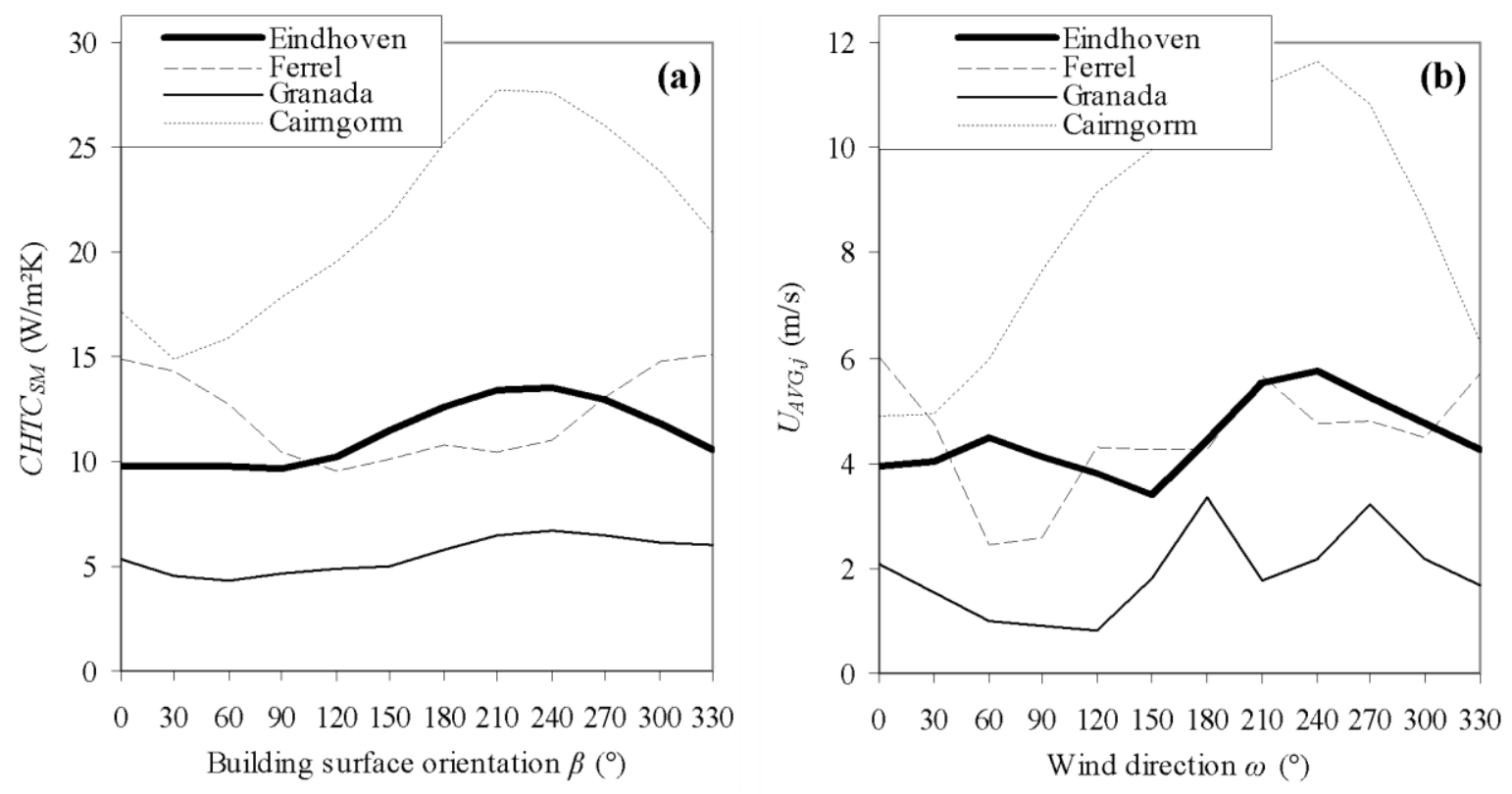

Figure 9: Comparison of different wind climates: (a) $\mathrm{CHTC}_{S M}$ as a function of building surface orientation; (b) Average wind speed $\left(U_{A V G, j}\right)$ as a function of wind direction. 
Defraeye T., Carmeliet J. (2010), A methodology to assess the influence of local wind conditions and building orientation on the convective heat transfer at building surfaces, Environmental Modelling \& Software 25 (12), 1813-1824. http://dx.doi.org/10.1016/i.envsoft.2010.06.002

Tables

Table 1: Percentages of occurrence $\left(x_{i j}\right)$ of $U_{p o t}\left(=U_{10}\right.$ in this study) for several wind speeds categories $(i)$ and for 12 wind direction categories $(j)$, for the meteorological station of Eindhoven for the period 19712000. $U_{10, i}$ indicates the average wind speed of a certain wind speed category. Var/Calm indicates the percentage of occurrence of wind conditions where the wind direction could not clearly be determined due to strong fluctuations or where there is no or a very low wind speed.

\begin{tabular}{|c|c|c|c|c|c|c|c|c|c|c|c|c|c|c|c|}
\hline \multirow{3}{*}{$\begin{array}{l}i \\
\downarrow\end{array}$} & \multicolumn{15}{|c|}{ Wind direction } \\
\hline & \multirow[t]{2}{*}{$j \rightarrow$} & Var/ & $\mathrm{N}$ & NNE & NEE & $\mathrm{E}$ & SEE & SSE & $\mathrm{S}$ & SSW & SWW & $\mathrm{W}$ & NWW & NNW & \multirow[b]{2}{*}{$j^{x_{i j}}$} \\
\hline & & Calm & $0^{\circ}$ & $30^{\circ}$ & $60^{\circ}$ & $90^{\circ}$ & $120^{\circ}$ & $150^{\circ}$ & $180^{\circ}$ & $210^{\circ}$ & $240^{\circ}$ & $270^{\circ}$ & $300^{\circ}$ & $330^{\circ}$ & \\
\hline Interval & $U_{10, i}$ & & & & & & & & & & & & & & \\
\hline $0-1$ & 0.5 & 2.2 & 0.12 & 0.11 & 0.07 & 0.07 & 0.11 & 0.19 & 0.13 & 0.15 & 0.16 & 0.13 & 0.14 & 0.15 & 3.73 \\
\hline $1-2$ & 1.5 & 1.54 & 0.72 & 0.85 & 0.66 & 0.58 & 0.79 & 1.12 & 0.93 & 1.02 & 0.81 & 0.8 & 0.76 & 0.69 & 11.27 \\
\hline $2-3$ & 2.5 & 0.34 & 0.92 & 1.37 & 1.35 & 0.92 & 1.37 & 1.56 & 1.41 & 1.76 & 1.52 & 1.39 & 0.98 & 0.93 & 15.82 \\
\hline $3-4$ & 3.5 & 0.03 & 0.98 & 1.42 & 1.21 & 0.92 & 1.25 & 1.46 & 1.57 & 2.21 & 2 & 1.4 & 1 & 0.88 & 16.33 \\
\hline $4-5$ & 4.5 & & 0.79 & 1.1 & 1.34 & 0.84 & 1.05 & 1.05 & 1.44 & 2.09 & 2.06 & 1.34 & 0.89 & 0.74 & 14.73 \\
\hline $5-6$ & 5.5 & & 0.4 & 0.66 & 0.99 & 0.57 & 0.63 & 0.46 & 1.02 & 1.82 & 1.69 & 1.02 & 0.53 & 0.46 & 10.25 \\
\hline $6-7$ & 6.5 & & 0.39 & 0.6 & 0.84 & 0.44 & 0.4 & 0.26 & 0.84 & 2.18 & 2.35 & 0.98 & 0.62 & 0.47 & 10.37 \\
\hline $7-8$ & 7.5 & & 0.25 & 0.36 & 0.56 & 0.27 & 0.21 & 0.13 & 0.57 & 1.72 & 1.76 & 0.87 & 0.56 & 0.37 & 7.63 \\
\hline $8-9$ & 8.5 & & 0.1 & 0.15 & 0.2 & 0.1 & 0.08 & 0.04 & 0.29 & 0.97 & 1.2 & 0.58 & 0.28 & 0.18 & 4.17 \\
\hline $9-10$ & 9.5 & & 0.05 & 0.07 & 0.11 & 0.04 & 0.04 & 0.02 & 0.13 & 0.68 & 0.7 & 0.37 & 0.19 & 0.09 & 2.49 \\
\hline $10-11$ & 10.5 & & 0.03 & 0.02 & 0.05 & 0.02 & 0.02 & 0.01 & 0.08 & 0.44 & 0.48 & 0.23 & 0.1 & 0.04 & 1.52 \\
\hline $11-12$ & 11.5 & & 0.01 & 0.01 & 0.02 & & & & 0.03 & 0.21 & 0.28 & 0.12 & 0.05 & 0.02 & 0.75 \\
\hline $12-13$ & 12.5 & & & & & & & & 0.01 & 0.15 & 0.16 & 0.11 & 0.05 & 0.01 & 0.49 \\
\hline 13-14 & 13.5 & & & & & & & & & 0.06 & 0.08 & 0.06 & 0.02 & & 0.22 \\
\hline $14-15$ & 14.5 & & & & & & & & & 0.03 & 0.04 & 0.03 & 0.02 & & 0.12 \\
\hline $15-16$ & 15.5 & & & & & & & & & 0.02 & 0.02 & 0.02 & & & 0.06 \\
\hline $16-17$ & 16.5 & & & & & & & & & & 0.01 & 0.01 & & & 0.02 \\
\hline $17-18$ & 17.5 & & & & & & & & & & & 0.01 & & & 0.01 \\
\hline \multicolumn{16}{|c|}{ 18-higher } \\
\hline$\sum x_{i j}$ & & 4.11 & 4.76 & 6.72 & 7.4 & 4.77 & 5.95 & 6.3 & 8.45 & 15.51 & 15.32 & 9.47 & 6.19 & 5.03 & 100 \\
\hline
\end{tabular}

Table 2: Relative difference of the surface-averaged $C H T C$ on the surfaces of a cube in channel flow between the CFD validation study of Defraeye et al. (2010a) $\left(\mathrm{CHTC}_{S I M}\right)$ and the wind-tunnel experiment of Meinders et al. (1999) $\left(\right.$ CHTC $\left._{E X P}\right)$.

\begin{tabular}{lc}
\hline Surface & CHTC $_{S I M}-C_{\text {CHTC }}$ \\
\hline Windward & $7 \%$ \\
\hline Leeward & $21 \%$ \\
\hline Side & $12 \%$ \\
\hline Top & $33 \%$ \\
\hline
\end{tabular}

Table 3: Coefficient $A_{\varphi}$, exponent $B_{\varphi}$ and correlation coefficient $R_{\varphi}$ of the $C H T C-U_{10}$ power-law correlations for a building surface, for different incidence angles $\varphi$, obtained by CFD simulations.

\begin{tabular}{lccc}
\hline Incidence angle $\varphi$ & $A_{\varphi}$ & $B_{\varphi}$ & $R_{\varphi}$ \\
\hline $0^{\circ}$ & 4.90 & 0.86 & 1.000 \\
\hline $30^{\circ}, 330^{\circ}$ & 4.63 & 0.87 & 1.000 \\
\hline $60^{\circ}, 300^{\circ}$ & 4.25 & 0.88 & 1.000 \\
\hline $90^{\circ}, 270^{\circ}$ & 2.78 & 0.87 & 1.000 \\
\hline $120^{\circ}, 240^{\circ}$ & 1.44 & 0.83 & 1.000 \\
\hline $150^{\circ}, 210^{\circ}$ & 1.85 & 0.84 & 1.000 \\
\hline $180^{\circ}$ & 2.25 & 0.84 & 0.999 \\
\hline
\end{tabular}


Defraeye T., Carmeliet J. (2010), A methodology to assess the influence of local wind conditions and building orientation on the convective heat transfer at building surfaces, Environmental Modelling \& Software 25 (12), 1813-1824. http://dx.doi.org/10.1016/i.envsoft.2010.06.002

Table 4: Multiplication factors $\left(\chi_{\varphi}\right)$ for different incidence angles $\varphi$ (determined for $U_{10}=0.5 \mathrm{~m} / \mathrm{s}$ ).

\begin{tabular}{lc}
\hline Incidence angle $\varphi$ & $\chi_{\varphi}$ \\
\hline $0^{\circ}$ & 1.00 \\
\hline $30^{\circ}, 330^{\circ}$ & 0.94 \\
\hline $60^{\circ}, 300^{\circ}$ & 0.86 \\
\hline $90^{\circ}, 270^{\circ}$ & 0.56 \\
\hline $120^{\circ}, 240^{\circ}$ & 0.30 \\
\hline $150^{\circ}, 210^{\circ}$ & 0.38 \\
\hline $180^{\circ}$ & 0.47 \\
\hline
\end{tabular}

Table 5: Mean wind speed $U_{\text {mean }}$ and mean CHTC $_{S M}$ for different building sites.

\begin{tabular}{lcc}
\hline Location & $U_{\text {mean }}(\mathrm{m} / \mathrm{s})$ & Mean $C H T C_{S M}\left(\mathrm{~W} / \mathrm{m}^{2} \mathrm{~K}\right)$ \\
\hline Eindhoven & 4.5 & 11.3 \\
\hline Ferrel & 5.1 & 12.3 \\
\hline Granada & 2.1 & 5.5 \\
\hline Cairngorm & 9.7 & 21.5 \\
\hline
\end{tabular}

